The Sustainability Cycle and Loop: models for a more unified understanding of sustainability

Laura Hay, Alex Duffy ${ }^{b}$, R. I. Whitfield ${ }^{c}$

aCorresponding author:

Department of Design, Manufacture, and Engineering Management, 131 Rottenrow,

University of Strathclyde,

Glasgow,

G4 0NG

United Kingdom

email: laura.hay@strath.ac.uk

tel: +447772019910

bDepartment of Design, Manufacture, and Engineering Management, 131 Rottenrow,

University of Strathclyde,

Glasgow,

G4 0NG

United Kingdom

email: alex.duffy@strath.ac.uk

cDepartment of Design, Manufacture, and Engineering Management, 131 Rottenrow,

University of Strathclyde,

Glasgow,

G4 0NG

United Kingdom

email: ian.whitfield@strath.ac.uk 


\section{The Sustainability Cycle and Loop: models for a more unified understanding of sustainability}

Laura Hay, Alex Duffy, R. I. Whitfield

Department of Design, Manufacture and Engineering Management, University of Strathclyde, Glasgow

\section{Abstract}

In spite of the considerable research on sustainability, reports suggest that we are barely any closer to a more sustainable society. As such, there is an urgent need to improve the effectiveness of human efforts towards sustainability. A clearer and more unified understanding of sustainability among different people and sectors could help facilitate this. This paper presents the results of an inductive literature investigation, aiming to develop models to explain the nature of sustainability in the Earth system, and how humans can effectively strive for it. The major contributions are two general and complementary models, that may be applied in any context to provide a common basis for understanding sustainability: the Sustainability Cycle (S-Cycle), and the Sustainability Loop (S-Loop). Literature spanning multiple sectors is examined from the perspective of three concepts, emerging as significant in relation to our aim. Systems are shown to provide the context for human action towards sustainability, and the nature of the Earth system and its sub-systems is explored. Activities are outlined as a fundamental target that humans need to sustain, since they produce the entities both needed and desired by society. The basic behaviour of activities operating in the Earth system is outlined. Finally, knowledge is positioned as the driver of human action towards sustainability, and the key components of knowledge involved are examined. The S-Cycle and S-Loop models are developed via a process of induction from the reviewed literature. The S-Cycle describes the operation of activities in a system from the perspective of sustainability. The sustainability of activities in a system depends upon the availability of resources, and the availability of resources depends upon the rate that activities consume and produce them. Humans may intervene in these dynamics via an iterative process of interpretation and action, described in the S-Loop model. The models are briefly applied to a system described in the literature. It is shown that the S-Loop may be used to guide efforts towards sustainability in a particular system of interest, by prescribing the basic activities involved. The S-Cycle may be applied complementary to the S-Loop, to support the interpretation of activity behaviour described in the latter. Given their general nature, the models provide the basis for a more unified understanding of sustainability. It is hoped that their use may go some way towards improving the effectiveness of human action towards sustainability. 
Keywords: sustainability; sustainability goals; sustainability indicators; sustainability model; activity sustainability

\section{Introduction}

The increasing scale of human activity on the planet has led to the emergence of sustainability as a central aim for society. In its most basic form, sustainability can be defined as the ability to sustain (Kajikawa, 2008), maintain (Lele and Norgaard, 1996; Marcuse, 1998), or continue (Dempsey et al., 2011; Shearman, 1990) something over time. Historically, the term has been used in a technical sense within specific disciplines to refer generally to the maintenance or continuation of some process or system over time (Kajikawa et al., 2007). Today, sustainability is an issue of concern primarily because of the mounting evidence to suggest that human activity in the Earth system is following an unsustainable trajectory. According to (UNEP, 2012, p.xviii), the "Earth System provides the basis for all human societies and their economic activities" in the form of resources and waste processing capacity. However, research suggests that human activity is degrading the Earth system that it depends upon for its continued operation (Rockström et al., 2009; UNEP, 2012). Highlighting the potential magnitude of the problem, Ehrlich and Ehrlich (2013. p.1) suggest that supporting today's population, consuming resources at the same rate as the United States, "would take four to five more Earths." In response, much of current sustainability research focuses on the sustainability of human society as an integral part of the Earth system (Beddoe et al., 2009; Komiyama and Takeuchi, 2006; Voinov, 2007).

Lindsey (2011, p.561) remarks that the "worldwide movement toward a more sustainable society has caught fire in recent years." The rising significance of sustainability research is reflected the expanding size of the literature that documents it. Querying 'sustainab*' through the Web of Knowledge service for all years up until 2012 returns over 53,000 records in total - in contrast, conducting the same search for all years up until 1980 returns just 70 results. Within this literature, a plethora of goals, indicators, and targets intended to facilitate a shift towards sustainability may be identified (Jordan et al., 2010; Parris and Kates, 2003; Quental et al., 2011). However, recent reports highlight a lack of progress towards sustainability at the societal level (e.g. Eurostat, 2011; UNEP, 2012), suggestive of ineffectual human action. It seems that in spite of the considerable body of research on sustainability, we are barely any closer to a more sustainable society. So why is this?

One issue that appears to be impeding progress is the lack of a clear and unified understanding of sustainability among different people and sectors (Lindsey, 2011; Voinov, 2007). For example, Hannon and Callaghan (2011, p.877) argue that "the diffusion and popularity of the term sustainability with relatively little corresponding rigorous and grounded conceptualization may have created confusion over the basic 
concepts of sustainability." In turn, they suggest that the "lack of a unified and rigorous understanding of sustainability means that sustainability initiatives are often ineffectual," a point made in a business context but readily translatable to society as a whole. For example, Kajikawa (2008, p.218) remarks that people have different ideas on sustainability in different contexts and as a result, "solutions tend to be sustainable within [individual] sectors rather than across the whole of society." This is reflected in the sustainability research landscape, which remains fractured along disciplinary boundaries (Kajikawa et al. 2007; Kajikawa 2008) in spite of calls for transdisciplinary approaches (Bodini, 2012; Sneddon et al., 2006). For example, there exist distinct areas of research dedicated to sustainability in specific sectors, e.g. agriculture, development, forestry, fisheries, and so on (Kajikawa, 2008). Within each area, a range of contextspecific sustainability definitions, goals, and indicators etc. may be identified (e.g. Eurostat, 2011; Standal and Utne, 2011; US Forest Service, 2010; Walter and Stützel, 2009). In summary, Lindsey (2011, p.561) remarks that, "While there seems to be considerable consensus that a more sustainable society is in the best interest of everyone, opinions regarding what sustainability really means and how to achieve it are as diverse as the entities striving for it." In response, he points to the need for "a consistent framework for human effectiveness in achieving sustainability."

There is an urgent need to improve the effectiveness of human efforts towards sustainability. A clearer and more unified understanding of sustainability among different people and sectors could help to facilitate this. Along these lines, this paper presents the results of an inductive literature investigation focusing on sustainability and human action towards it across society. The aim was to develop models to explain the nature of sustainability in the Earth system, and how humans in different sectors may effectively strive for it. Models may be viewed as "abstractions used by scientists and researchers to understand and explain natural phenomena or human behaviour phenomena" (Sim, 2000, p.17). In the context of sustainability, Kajikawa (2008, p.232) notes that "modeling is a fundamental and indispensable scientific activity." The major contributions made by this investigation are two general and complementary models, developed via a process of induction from the literature: (i) the Sustainability Cycle (SCycle), describing the operation of activities in a system from the perspective of sustainability; and (ii) the Sustainability Loop (S-Loop), describing a basic process that may lead humans towards sustainability.

Owing to the vastness of the sustainability literature, we focused our investigation on sources originating in sectors identified as major contributors to sustainability research: agriculture (Conway, 1986; Darnhofer et al., 2010; Hansen, 1996; Pretty, 2008; Tilman et al., 2002; Walter and Stützel, 2009), business (Dyllick and Hockerts, 2002; Figge and Hahn, 2005; Hahn and Figge, 2011; Hart and Milstein, 2003; Lo, 2010; Rainey, 2006), design (Chapman, 2011; Gagnon et al., 2012; Wahl and Baxter, 2008), development (Brown et al., 1987; Bodini, 2012; Burger and Christen, 2011; Dawson et al., 2010; 
Eurostat, 2011a; Holling, 2001; Jamieson, 1998; Lele and Norgaard, 1996; Rametsteiner et al., 2011; Shearman, 1990; UNDP, 2011; Vos, 2007; Vucetich and Nelson, 2010; Wackernagel and Yount, 1998; WCED, 1987), economics (Baumgärtner and Quaas, 2010; Brown and Ulgiati, 1997; Costanza and Daly, 1992; Daly, 1990; Derissen et al., 2011; Ekins et al., 2003; Heal, 2012; Neumayer, 2003; Odum, 1994; Solow, 1993), fisheries (Gaichas, 2008; Larkin, 1977; Norse et al., 2012; Standal and Utne, 2011), forestry (Hahn and Knoke, 2010; Noss, 1993; Pearce et al., 2003; Wiersum, 1995), urban studies (Dempsey et al., 2011; Maclaren, 1996; Marcuse, 1998), and sustainability science (Kajikawa 2008; Quental et al. 2010; Spangenberg 2011). We included literature from multiple sectors to gain a view that is as free from contextual nuances as possible.

Given our aim, we adopted an anthropocentric perspective throughout, although other perspectives are certainly possible (e.g. see Williams and Millington (2004) for an example). From our delimited corpus, three concepts emerged as significant for detailed investigation in relation to our aim of modelling to explain the nature of sustainability in the Earth system, and how humans in different sectors may effectively strive for it:

- Systems. As will be shown in Section 4, what is "sustainable" for one entity may in fact be detrimental to the sustainability of other entities that it is connected to (Alfaris et al., 2010; Voinov, 2007). As such, Bell and Morse (2008, p.110) suggest that, "In understanding sustainability [...] we need to recognize and work with unities, of which we, as observers, are also part." In other words, humans should not focus on the sustainability of isolated entities, but rather on the sustainability of entities as interconnected parts of a wider system (Bell and Morse, 2008; Bodini, 2012; Fiksel, 2003). Ultimately, the entities that humans wish to sustain are parts of the Earth system, of which humans themselves are also integral components. Owing to the scale and complexity of the Earth system, humans focus on sustainability in a number of different sub-systems, e.g. agricultural systems (Conway, 1986; Darnhofer et al., 2010; Hansen, 1996; Pretty, 2008), economies (Costanza and Daly 1992; Solow 1993; Brown and Ulgiati 1997; Ekins et al. 2003; Neumayer 2003), and urban areas (Maclaren 1996; Dempsey et al. 2011) (explored more deeply in Section 3). Thus, it may be seen that systems provide the context for human action towards sustainability.

- Activities. As will be discussed in Section 2, the multiplicity of human values means that different people want to sustain different things (Lele and Norgaard, 1996; Lindsey, 2011; Chapman, 2011). Examples of sustainability targets identifiable in the literature include resources (e.g. Dyllick and Hockerts, 2002; Neumayer, 2003; Standal and Utne, 2011), social phenomena and standards (e.g. Heal, 2012; Vos, 2007; Wackernagel and Yount, 1998), and the life of organisms 
and non-organic entities (e.g. Brown et al., 1987; Goerner et al., 2009; Heal, 2012; Jamieson, 1998). From this perspective, developing a common understanding of the nature of sustainability appears to be a difficult task (Lindsey, 2011). In this paper, our approach is to consider that activities are a fundamental target that humans need to sustain. In a system, activities may be viewed as "the fundamental elements that transform input to output" (O'Donnell and Duffy, 2005, p.56). For example, humans need production activities to transform raw materials into useful artefacts (Chapman, 2011), and socio-economic development activities to transform artefacts into intangible entities such as living standards and wellbeing (UNDP, 2011). We need certain natural activities to transform our waste products back into useful resources (Lindsey, 2011) such as water and minerals. At the most fundamental level, we need biological activities to transform food into energy, and air into the oxygen we need to live. Thus, in order to sustain a particular entity, we need to sustain the activities that produce that entity in the first place. Without activities, there would be no life and therefore no society to sustain. Like "system," "activity" is a general concept that may be translated to any context (O'Donnell and Duffy, 2005) (as shown in Section 4). Thus, discussing sustainability in terms of activities provides us with a general language that may be understood in any context.

- Knowledge. Knowledge may be viewed as a driver of human action, both generally and in efforts towards sustainability. For example, Newell (1982, p.100) describes knowledge generally as "a potential for generating action." In a similar vein, Meadows (1998, p.3) positions knowledge of "the discrepancy between the desired state or goal and the perceived state of [a] system" as a driver of human action towards sustainability. As we will show in Section 5, to make informed decisions in efforts towards sustainability, humans need knowledge on the system they are intervening in and the activities they are trying to manage. More fundamentally, they need to develop effective means to gather this knowledge. Thus, as is the case in other spheres, being equipped with adequate knowledge may be viewed as crucial to the effectiveness of human action towards sustainability.

In Sections 3, 4, and 5, we present the findings of a review of the literature (outlined previously) from the perspective of each of the above concepts. On the basis of these findings, we constructed the S-Cycle and S-Loop models via a process of induction. The S-Cycle model describes the Earth system and its sub-systems as being comprised of renewable and non-renewable resource stocks, that are consumed and replenished by both natural and human activities. These activities transform input flows of renewable and non-renewable resources into output flows of: (i) intended resources, i.e. entities intended for use in the activity itself; (ii) intended yield, i.e. entities to be yielded to the wider system, either to be used in other activities or to contribute to resource stocks in 
the system; and (iii) waste, i.e. entities with no utility to the activity, that may be used in other activities or contribute to waste accumulations in the system. The ability of activities in the system to continue to operate fundamentally depends upon the availability of resources in the system. In turn, the availability of resources in the system fundamentally depends upon the rate at which they are consumed and produced by activities. Humans may intervene in these dynamics by implementing sustainability goals and indicators for activities, as described in the S-Loop model below.

The S-Loop model describes human efforts towards sustainability as an iterative process of interpretation and action involving the aforementioned three concepts. In the S-Loop, humans interpret the behaviour of activities in a system to produce knowledge on: (i) their current behaviour; and (ii) how the activities should behave for sustainability, i.e. sustainability goal knowledge. This knowledge serves as a basis for suggesting and implementing actions that are expected to result in the activities fulfilling their sustainability goals. Humans then interpret the behaviour of activities after actions have been taken, by evaluating sustainability indicators to produce knowledge on resulting activity behaviour in relation to sustainability goals. This knowledge may then be used as a basis for suggesting and implementing further actions. For instance, if activities are found not to be on track to fulfil their sustainability goals, humans may suggest actions that are expected to result in the goals being fulfilled in future. Alternatively, they may use this knowledge as a basis from which to begin the whole process again in the context of a different system of interest, having learned from experience.

The S-Loop can provide guidance on how to intervene in a particular system of interest (e.g. businesses, production systems, and organisations generally) in efforts towards sustainability. A key activity described in the S-Loop model is interpreting the behaviour of activities in a particular system of interest, to produce knowledge on current behaviour and sustainability goals. The S-Cycle model can support this activity, by highlighting the aspects of activity behaviour that fundamentally affect sustainability in a system. Thus, the S-Cycle can be applied complementary to the S-Loop, to analyse and understand the behaviour of activities in a system of interest. More fundamentally, the S-Cycle can explain the nature of sustainability in the Earth system in general terms and thus, provides a common language for discussing sustainability both within and across different sectors. Given their general nature, the models provide the basis for a more unified understanding of sustainability among different people and sectors Further research is under way to explore the validity and applications of the models. However, it is hoped that their use may go some way towards improving the effectiveness of human action towards sustainability.

The remainder of the paper is organised as follows. In Section 2, we briefly consider different definitions and interpretations of sustainability identifiable in the literature, 
and explicate the interpretation that guided our investigation. In Sections 3, 4, and 5, we present the findings of a literature review on human action towards sustainability from the perspective of systems, activities, and knowledge, as discussed above. In Section 6, we show how these findings were used to construct the S-Cycle and S-Loop models. A brief demonstration of the models is also provided. The paper concludes with a summary of the work in Section 7.

\section{What is sustainability?}

A definition of sustainability is often the starting point for human efforts towards sustainability (Hannon and Callaghan, 2011; van Zeijl-Rozema and Martens, 2010; Walter and Stützel, 2009). Indeed, if "sustainability" is our goal, then it seems reasonable to suggest that we need some grasp on what exactly this goal represents. As Bell and Morse (2008, p.11) exclaim, "how can we do something unless we know what we are trying to do?" In its most literal form, sustainability simply means the ability to sustain something (Kajikawa, 2008). To gain a deeper understanding of the term, authors have undertaken lexical examinations focusing primarily on the meaning and etymology of "sustain" (Brown et al., 1987; Jamieson, 1998; Kirsch, 2009; Lele and Norgaard, 1996; Shearman, 1990), leading to alternative definitions: the ability to maintain something (Lele and Norgaard, 1996; Marcuse, 1998), and the ability to continue something (Dempsey et al., 2011; Shearman, 1990). Voinov (2007, p.489) appears to suggest that these terms are essentially synonymous, writing that all definitions of sustainability "talk about maintenance, sustenance, continuity of a certain resource, system, condition, relationship." Indeed, from the perspective of dictionary entries at least, the terms "sustain," "maintain," and "continue" hold similar meanings (OED, 2012). Thus, we shall employ them synonymously throughout this paper.

The lexical definitions above are rather abstract - they refer to sustaining something, without specifying what that thing is or how long it is to be sustained for. In order to move from these abstract interpretations of sustainability to a more concrete definition, humans decide what is to be sustained, and for how long (Lele and Norgaard, 1996; Solow, 1993; Vos, 2007). Lele and Norgaard (1996) argue that in executing such decisions, humans must make value judgements. In other words, as humans, what we choose to sustain and for how long depends upon what we value (Chapman, 2011; Lindsey, 2011; Liu et al., 2010). At the highest level, we seem to agree that we want human society to continue as an integral part of the Earth system. However, precisely what kind of society is a matter for considerable debate (Kajikawa, 2008; Parris and Kates, 2003). By specifying exactly what we want to sustain and for how long in a particular context, we may develop more specific definitions of sustainability (Lele and Norgaard, 1996). Vos (2007, p.335) remarks that specific definitions of sustainability "must number in the hundreds." Given that different people have different value 
criteria and thus, will naturally consider different things as valuable sustainability targets, this is perhaps unsurprising.

Above, we have implicitly assumed that sustainability is an ability. That is, the ability to sustain is fundamentally an ability in the same vein as the ability to drive a car, the ability to read, and the ability to write (although these are all qualitatively different abilities). It would seem that the lexical definitions of sustainability as the ability to sustain, maintain, or continue something unequivocally point to this interpretation. However, alternative interpretations of sustainability emerge from the literature, including: a process of change (e.g. Kim and Oki, 2011; Wahl and Baxter, 2008); a property or attribute of an entity (e.g. Bodini, 2012; Wahl and Baxter, 2008); and a state of some kind (e.g. Goerner et al., 2009; Heal, 2012). All of these interpretations appear to refer to different "things." Before we can develop models to explain the nature of sustainability in the Earth system, and how humans may effectively strive for it, we need a clear grasp on what kind of "thing" sustainability actually is. To this end, in Section 2.1 we briefly explore the different interpretations of sustainability identifiable in the literature. In Section 2.2, we show how these different interpretations can be made more coherent by considering the nature of "ability" generally, and explicate the interpretation of sustainability that guided our investigation.

\subsection{Interpretations of sustainability in the literature}

In addition to interpretations of sustainability as an ability (e.g. Dempsey et al., 2011; Hansen, 1996; Kajikawa, 2008), sustainability may also be described as a process of change. In this vein, Kim and Oki (2011, p.248) remark that sustainability is a "dynamic process that requires building resilience and an ability to manage it wisely." Similarly, Wahl and Baxter (2008, p.72) describe sustainability as a "continuous process of learning and adaptation." Wahl and Baxter also highlight another interpretation: sustainability as a property or attribute of an entity 1 . They refer to sustainability as "an emergent property of appropriate interactions and relationships among active participants in the complex cultural, social, and ecological processes that constitute life in the twenty-first century" (Wahl and Baxter, 2008, p.73). Along similar lines, Bodini (2012, p. 140) remarks that sustainability "is an overall attribute that emerges from the internal processes that characterize human-environmental systems." Yet another interpretation is sustainability as some kind of state of an entity. For instance, in the context of flow-networks Goerner et al. (2009, p. 77) suggest that "sustainability can reasonably be defined as the optimal balance of efficiency and resilience" in a flow-

\footnotetext{
${ }^{1}$ Generally speaking, we would consider a "property" and an "attribute" to be slightly different concepts. We view both as referring to particular qualities of an entity; however, we view a property as an intrinsic quality of an entity, and an attribute as a quality that is ascribed to an entity by humans. For instance, a person may have a certain height as a property, and the attribute of being either tall or short. Nonetheless, in the sustainability literature (as in other contexts), the term "attribute" appears to be used as a synonym for "property," and thus we consider "attribute" as such here.
} 
network, i.e. some optimal state of the network. In a similar vein, Heal (2012, p. 153) suggests that sustainability "is a potential dynamic equilibrium of some type," i.e. a state of equilibrium.

\subsection{The nature of ability}

Sustainability is a compound word: sustain + ability. Thus, it may seem rather incongruous to describe sustainability as anything other than an ability. However, examining the nature of "ability" generally suggests that the interpretations of sustainability presented in Section 2.1 are likely to be complementary rather than conflicting. For example, an ability may be described as a property of an entity, that is manifested to humans as behaviour that produces certain effects (Hubka and Eder, 1988; Wang et al., 2008). From this perspective, we may say that the sustainability of an entity is manifested to humans as behaviour that produces the effect of maintenance/continuation, either of the entity in question or some other target. What humans call "sustainability" may be viewed as a property of an entity that exhibits this kind of behaviour. Human cognizance of the property of sustainability results from an assessment of an entity's behaviour, showing that the entity can actually produce the effect of maintenance/continuation (Wang et al., 2008). Until this assessment is made, we may posit that an entity has the ability to sustain the chosen target, on the basis of our knowledge of the entity. But we cannot say that it actually has this ability until we have assessed its behaviour and confirmed that it can indeed sustain the target in question. This point is supported by authors in the sustainability literature. For instance, Costanza and Patten (1995, p.194) write that "determinations of sustainability can only be made after the fact." Similarly, Conway (1986, p.23) remarks that "measurement [of sustainability] is difficult and can often only be done retrospectively." Essentially, sustainability (particularly at the societal level) is often a long term goal, that we may never be able to say we have "attained". Rather, we may continually strive for it and keep track of our progress towards (or away from) it by assessing behaviour.

Above, we have shown that when considered as an ability, sustainability may simultaneously be viewed as a property of an entity (Wang et al., 2008). As discussed above, two further interpretations of the nature of sustainability may be identified in the literature: (i) a process of change (e.g. Kim and Oki, 2011; Wahl and Baxter, 2008), and (ii) a state of some kind (e.g. Goerner et al., 2009; Heal, 2012). Like "ability" and "property," we suggest that these interpretations simply describe different views on the sustainability concept. Firstly, much has been written on the need to transition towards sustainability (Parris and Kates, 2003; Quental et al., 2010). It may clearly be seen from the above that this is a behavioural direction - humans are trying to shift the current behaviour of entities towards the behaviour required for sustainability. With respect to (i), it is clear that in efforts towards sustainability, some kind of process of change is occuring with respect to the behaviour of certain entities. Secondly, as discussed, 
sustainability is manifested to humans as behaviour that produces the effect of sustenance/ maintenance/continuation (Wang et al., 2008). With respect to (ii), we may consider this manifestation as a kind of state of an entity. That is, the entity is perceived to be behaving in a particular manner (OED, 2012).

In summary, we interpret sustainability as an ability, that is in turn a property of an entity, and manifested to humans as behaviour that produces the effect of maintenance/continuation, either of the entity in question or some other target. In Section 1, it was shown that systems, activities, and knowledge emerge from the literature as key concepts in relation to our aim of modelling to explain the nature of sustainability in the Earth system, and how humans may effectively strive for it. In turn, the findings of a literature review conducted from the perspective of each of these concepts served as a basis for developing two general models via induction: (i) the SCycle, and (ii) the S-Loop (introduced in Section 6). Having outlined what we mean by "sustainability," we present the findings of this literature review in Sections 3, 4, and 5.

\section{The systems context for sustainability}

As discussed in Section 1, systems may be viewed as providing the context for human action towards sustainability. In this vein, Voinov (2007, p.488) suggests that sustainability may be viewed as "a human intervention that is imposed on a system as part of human activity and is totally controlled and managed by humans." Humans are primarily concerned with the sustainability of their society within the Earth system (Beddoe et al., 2009; Komiyama and Takeuchi, 2006; Voinov, 2007), although they tend to focus on different sub-systems of this overall system in order to reduce complexity. To provide insight into the context for human action towards sustainability, we examine and conceptualise the Earth system and its sub-systems in the following sections. In Section 3.1, the general concept of a system is defined, and the relationship between function, behaviour, and structure in a system is delineated. In Section 3.2, the Earth system is outlined. In turn, different sub-systems of the Earth system that commonly form the foci of human efforts towards sustainability are presented.

\subsection{What is a system?}

Like definitions of sustainability, definitions of "system" abound (Bell and Morse, 2008). However, on a basic level and in a generic sense, a system may be defined as "a collection of elements, also called parts [or components by certain authors], that are each interrelated with at least one other, and which possesses properties different from the collection of properties of the individual parts" (Thomé, 1993, p.4). Thomé (1993, p.5) remarks that systems "are in the eye of the beholder." In other words, systems exist in the "real" world, but must be defined by humans in order to be studied. The author explains that "an observer, through a conscious act of her/his own, chooses to 
delimit something, that is a system, from its environment." They suggest that "this act follows a purpose of the system that is not necessarily intrinsic to this system but that the observer has in mind." Meadows (2008, p.15) suggests that the terms "purpose" and "function" mean essentially the same thing, i.e. what the system is for (Gero and Kannengiesser, 2004). However, "function is generally used for a nonhuman system, [and] the word purpose for a human one." She goes on to state that this distinction "is not absolute, since so many systems have both human and nonhuman elements" (Meadows, 2008, p.15). We shall use the term "function" throughout this paper to refer to "what a system is for." A system may fulfil its function by exhibiting a certain purposeful behaviour (Hubka and Eder, 1988; Wang et al., 2008).

According to Meadows (2008, pp.1-2), a "central insight of systems theory" is the notion that a "system, to a large extent, causes its own behaviour." She writes that a "system may be buffeted, constricted, triggered, or driven by outside forces. But the system's response to these forces is characteristic of itself." Along these lines, Tully (1993, p.46) remarks that the behaviour of a system is "determined by its structure and the stimuli it actually receives." Essentially, system behaviour may be viewed as an emergent property (Tully, 1993). That is, a property that "is not determined solely from the properties of the system's parts, but which is additionally determined by the system's structure" (Thomé, 1993, p.7). Behaviour refers to what a system does and, as discussed above, how it achieves its functions (Gero and Kannengiesser, 2004; Wang et al., 2008). The structure of a system, on the other hand, refers to "what its components are, how they are connected, and what passes across those connections" (Tully, 1993, p.46). Therefore, it may be seen that the notion of "structure" encompasses both the components of a system, and the relationships among them (Gero and Kannengiesser, 2004; Meadows, 2008). The behaviour of a system is exhibited by its structure, i.e. by its components and relationships (Gero and Kannengiesser, 2004; Wang et al., 2008). That is, humans can "see" the behaviour of a system by observing what its interrelated components do in a particular environment. Hubka and Eder (1988, p.246) highlight that a particular behaviour "does not determine a unique structure." As such, the same kind of behaviour can be exhibited by systems with different structures.

To exemplify the concept of a system, let us consider the context of agriculture. In striving for agricultural sustainability, we may choose to define a particular farm as a system (Darnhofer et al., 2010). We may consider the function of the farm to be, for instance, supplying humans with food and materials (Walter and Stützel, 2009). We may draw a boundary, whereby everything falling within may be considered to be part of the farm, and everything lying outside as part of the farm's environment. A multitude of components may be contained within the system boundary, such as land, machinery, fuel, livestock, feedstock, plants, buildings, humans, and so on (Darnhofer et al., 2010). In turn, these components may be interrelated in a variety of ways. For example, fuel may be used to power machinery and heat buildings, humans may operate machinery to 
produce feedstock from plants that are harvested from the land, feedstock may be consumed by livestock, livestock may be housed in buildings, and so on. The farm's immediate environment may be a rural locality, containing other farms, villages, towns, etc. (Darnhofer et al., 2010). The purposeful behaviour exhibited by the system in relation to its function may include growing and harvesting certain crops intended for consumption by humans as food and materials, and breeding and selling livestock intended for slaughter and eventual consumption by humans (Tilman et al., 2002).

\subsection{The Earth system}

Thomé (1993, p.5) remarks that it is "hard to imagine anything that could not be regarded as a system." Skyttner (1996, p.32) highlights the work of Kenneth Boulding (1964), who suggests that, "Everything that exists, whether formal, existential, or psychological, is an organized system of matter, energy, and information." At the highest level, we may even view the whole universe as a system (Brown et al., 2004). Blanchard and Fabrycky (1981, p.5) highlight that, "Since every system is made up of components, any component can be broken down into smaller components. If two hierarchical levels are involved in a given system, the lower is conveniently called a subsystem." In this way, it may be seen that galaxies can be thought of as subsystems of the universe. In turn, galaxies may be broken down into stellar systems, which may then be broken down into solar systems, which may once again be broken down into subsystems such as the Sun and the individual planets (in the case of our own solar system). As discussed above, it may be seen that the Earth system provides the ultimate context for human action towards sustainability (UNEP, 2012).

The Earth system may be viewed as a socio-ecological system (Beddoe et al., 2009). In other words, a system where "society and nature are innately coupled" (Dawson et al., 2010, p.2844). As such, it may be seen that humans are integral components of the system. However, they may also intervene in the system and its subsystems (Beddoe et al., 2009; Dawson et al., 2010). Further, given certain assumptions regarding the negligibility of material inputs and outputs (e.g. owing to space travel and asteroids), the Earth system may be approximated as thermodynamically closed (Daly 1992; Wackernagel and Rees 1997; Cabezas et al. 2005). That is, no mass crosses the system boundary. Only energy crosses the boundary, in the form of heat and work interactions (Çengel and Turner, 2004). A basic function of the Earth system and its sub-systems is processing materials, energy, and information (MEI). Blanchard and Fabrycky (1981, p.4) highlight that some "motive force must be present to provide the alteration." In the context of the whole Earth system, it may be seen that ultimately, this motive force is provided by incoming electromagetic radiation from the Sun (Stremke et al., 2011).

The Earth system may be broken down into a variety of "open, coupled, complex, interactive and non-linear dynamic [sub-]systems" (Dawson et al., 2010, p.2843). Major 
sub-systems of the Earth system considered in human efforts towards sustainability include: agricultural systems (e.g. Conway, 1986; Darnhofer et al., 2010; Hansen, 1996; Pretty, 2008); complex systems generally (e.g. Holling 2001; Voinov 2007; Goerner et al. 2009; Dawson et al. 2010; Bodini 2012); economies (e.g. Costanza and Daly 1992; Solow 1993; Brown and Ulgiati 1997; Ekins et al. 2003; Neumayer 2003); ecosystems (e.g. Brown et al. 1987; Gatto 1995; Goerner et al. 2009); organisms (e.g. Costanza and Daly 1992); urban areas (e.g. Maclaren 1996; Dempsey et al. 2011); and societies (e.g. Brown et al. 1987; Dempsey et al. 2011). These systems may be seen to exist at various hierarchical levels. For instance, a human (i.e. organism) may be viewed as a subsystem of a society, which in turn may be viewed as a sub-system of an ecosystem (Köhn, 1998). Given the size of the sustainability literature as discussed in Section 1, the range of systems presented here is not intended to be a comprehensive or absolute representation of all such entities studied in sustainability research. Rather, it is intended to convey those systems that emerge most prominently from the literature as key foci of sustainability research.

As discussed in Section 2, different people want to sustain different things within the Earth system (Lele and Norgaard, 1996; Lindsey, 2011; Chapman, 2011), leading to hundreds of different definitions of sustainability (Vos, 2007). From this perspective, developing a common understanding of sustainability seems to be a difficult task (Lindsey, 2011). In this paper, our approach is to consider that activities are a fundamental target that humans need to sustain. In Section 4, we introduce the general concept of an activity, illustrate the basic behaviour of activities in the Earth system, and show how humans can influence this behaviour towards what is required for sustainability within the system.

\section{Sustainable activities}

In Section 2, it was shown that sustainability may be generally defined as the ability to sustain (Kajikawa, 2008), maintain (Lele and Norgaard, 1996; Marcuse, 1998), or continue (Dempsey et al., 2011; Shearman, 1990) something. In Section 3, the context for human action towards sustainability, i.e. the Earth system and its sub-systems, was outlined. What humans choose to sustain within this system depends upon what they value (Chapman, 2011; Lindsey, 2011; Liu et al., 2010), as discussed in Section 2. Since different people have different value criteria (Reber, 2011), they want to sustain different things (Lele and Norgaard, 1996; Lindsey, 2011; Chapman, 2011). In turn, a plethora of specific definitions of sustainability may be identified in the literature, focusing on different targets to be sustained in different contexts (Vos, 2007). From this perspective, developing a common understanding of the nature of sustainability seems to be a difficult task (Lindsey, 2011). As discussed in Section 1, our approach in this paper is to consider that activities are a fundamental target that humans need to sustain. 
In a system, activities may be viewed as "the fundamental elements that transform input to output" (O'Donnell and Duffy, 2005, p.56). For example, humans need production activities to transform raw materials into useful artefacts (Chapman, 2011), and socioeconomic development activities to transform artefacts into intangible entities such as living standards and wellbeing (UNDP, 2011). We need certain natural activities to transform our waste products back into useful resources (Lindsey, 2011) such as water and minerals. At the most fundamental level, we need biological activities to transform food into energy, and air into the oxygen we need to live. Thus, in order to sustain a particular entity, we need to ensure the continued operation of the activities that produce that entity in the first place. Without activities, there would be no life and therefore no society to sustain. Like "system," "activity" is a general concept that may be translated to any context (as shown in the following sections). Thus, discussing sustainability in terms of activities provides us with a general language that may be understood in any context.

In the following sections, we introduce the concept of an activity in the context of the Earth system. In Section 4.1, an activity is defined as a physical or cognitive action that is directed by goals. It is shown that the sustainability of an activity in the Earth system may be considered to be manifested as behaviour that is conducive to the activity's continued operation within the system. In Section 4.2, the basic behaviour of activities operating in the Earth system is discussed. Finally, in Section 4.3, the kinds of relationships that may exist among activities in the Earth system are delineated. In turn, it is shown that sustainability may be viewed either as a property of an individual activity in a system, or an emergent property of a particular system of interest. Humans may influence activities in a system towards what is required for sustainability by implementing activity sustainability goals.

\subsection{What is an activity?}

An activity may be defined as a goal-directed physical or cognitive action, where a set of passive resources are used by active resources to produce an output that should satisfy the goal of the activity, as shown in Figure 1 (Boyle et al., 2009). Active resources may be viewed as resources that use other resources in activities and may "perform decision-making tasks," and passive resources as resources used by active resources (Boyle et al., 2009). For example, the information contained within defined goals may be considered to be a passive resource for use by active resources such as humans or intelligent software (Duffy, 2005). In a system, passive and active resources, and activity outputs, may be viewed as system components. The label of "passive resource," "active resource," or "output" that is attached to a particular system component depends upon the activities that it is involved in (explored more deeply in Section 4.2). In Section 3.1, it was shown that although systems exist in the "real" world, they must 
be defined by humans in order to be studied. The same point can be made regarding activities: although they operate in the "real" world, they must be defined by humans in order to be studied (O'Donnell and Duffy, 2005), e.g. by applying the formalism provided in Figure 1. From the work detailed in Duffy (2005, p. 65), it can be inferred that an active resource may be considered as "the means to carry out the activity," and a passive resource as providing "the conditions or elements upon which the means act." As such, it may be seen that the ability of an activity to continue to operate within a system, i.e. its sustainability, depends fundamentally upon the availability of passive and active resources in the system.

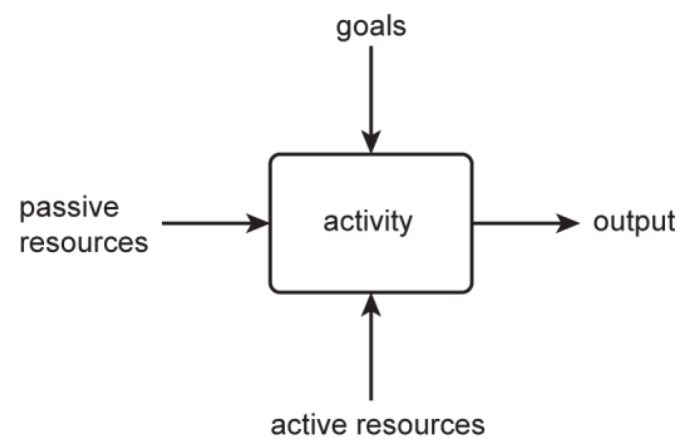

Fig 1. An activity, where active resources use passive resources to produce an output that meets the goal of the activity. The arrows indicate the direction of flow of material and/or cognitive entities.

Human action towards sustainability in the Earth system focuses on a range of different activities. These include:

- $\quad$ agricultural activities (Tilman et al., 2002; Walter and Stützel, 2009);

- business activities (Dyllick and Hockerts 2002; Hahn and Figge 2011; Hart and Milstein 2003; Lo 2010; Rainey 2006);

- design activities (Chapman, 2011; Wahl and Baxter, 2008) and the overall design process (Gagnon et al., 2012), given that an activity may be viewed as the basic component of a process (O'Donnell and Duffy, 2005);

- the overarching process of socio-economic development (Burger and Christen 2011; Eurostat 2011a; Holling 2001; UNDP, 2011; Vos 2007; Vucetich and Nelson 2010; Wackernagel and Yount 1998; WCED 1987);

- the activity of fishing (Larkin 1977; Norse et al. 2012; Standal and Utne 2011);

- activities undertaken in the use of forests (Noss 1993; Wiersum 1995), e.g. timber harvesting (Pearce et al., 2003); and

- activities involved in the production of yield generally, e.g. economic activity (Ekins et al., 2003; Figge and Hahn, 2005).

Again, given the size of the sustainability literature as discussed in Section 1, the range of activities presented here is not a comprehensive or absolute account. Rather, it is 
intended to convey those activities that emerge most prominently from the literature as key foci of sustainability research.

In Section 3.1, it was shown that the behaviour of a system refers to what the system does (Gero and Kannengiesser, 2004; Wang et al., 2008). It is exhibited by the structure of the system (Gero and Kannengiesser, 2004; Wang et al., 2008), i.e. its components and relationships (Tully, 1993). That is, humans can "see" the behaviour of a system by observing what its interrelated components do in a particular environment. Similarly, humans may focus on the behaviour of activities operating in a certain system, i.e. what the activities do within the system (Wang et al., 2008). We may consider this behaviour to be exhibited by the particular set of system components (i.e. passive and active resources, and outputs) involved in the activity. The sustainability of an entity is manifested to humans as behaviour that produces the effect of maintenance/continuation, either of the entity in question or some other target (Wang et al., 2008), as discussed in Section 2.2. As discussed above, in order to sustain the entities that humans value and that society depends upon, we need to ensure the continued operation of the activities that produce the entity in the first place. In other words, we need to ensure that these activities have the ability to continue operating over time. From this perspective, we may consider activity sustainability to be manifested as behaviour that produces the effect of continuation of the activity per se. In other words, behaviour that is conducive to the continued operation of the activity within the system. As we will show in Section 5.1, this behaviour is constrained by the physical laws and limits of the Earth system, and the moral and social standards of humans.

\subsection{Activity behaviour}

As shown in Section 2.2, the transition towards sustainability may be viewed as a behavioural direction. Thus, in seeking the sustainability of an activity in the Earth system, humans are attempting to shift its current behaviour towards the behaviour required for sustainability. That is, behaviour that is conducive to the activity's continued operation in the system. In doing so, humans may ensure the continued production of the entities that they value, and that society depends upon. To successfully facilitate a shift in activity behaviour, it is clearly necessary for humans to understand its basic nature. Along these lines, the behaviour of activities operating in the Earth system is outlined in the following paragraphs.

In the literature, the Earth system is typically viewed as containing various stocks of resources. According to Meadows (2008, p.17), a system stock is "a store, a quantity, an accumulation of material or information that has built up over time." Stocks of resources in the Earth system may be classed as either natural (e.g. forests, oceans, land, oil reserves, etc.) or artificial (e.g. economic capital stocks, industrial plant, 
information/knowledge databases, etc.) (Costanza and Daly 1992; Ekins 2011; Williams and Millington 2004). Further, these stocks may be classified as either renewable or non-renewable in nature (Brown and Ulgiati 1997; Campbell and Garmestani 2012; Daly 1990). That is, resource stocks that either regenerate over time (e.g. forests and oceans), or do not regenerate significantly along anthropological timescales (e.g. oil reserves), respectively (Daly, 1992).

An activity in the Earth system may use components from the above stocks as passive and active resources, to meet a need for resources as indicated by the goal of the activity. As discussed in Section 4.1, the sustainability of an activity in the Earth system fundamentally depends upon the availability of passive and active resources within the system. The term "resource" is defined thus: "A means of supplying a deficiency or need" (OED 2012). It may be seen that both natural and artificial system components may be used as resources in any type of activity. For example, natural activity has, over millions of years, produced crude oil that may be used as a passive resource in the anthropogenic activity of deep-sea drilling. Conversely, anthropogenic activity generates carbon dioxide that may be used as a passive resource by trees in the natural activity of photosynthesis. As discussed in Section 4.1, the active resources use the passive resources to produce outputs that should satisfy the goals of the activity, as shown in Figure 2.

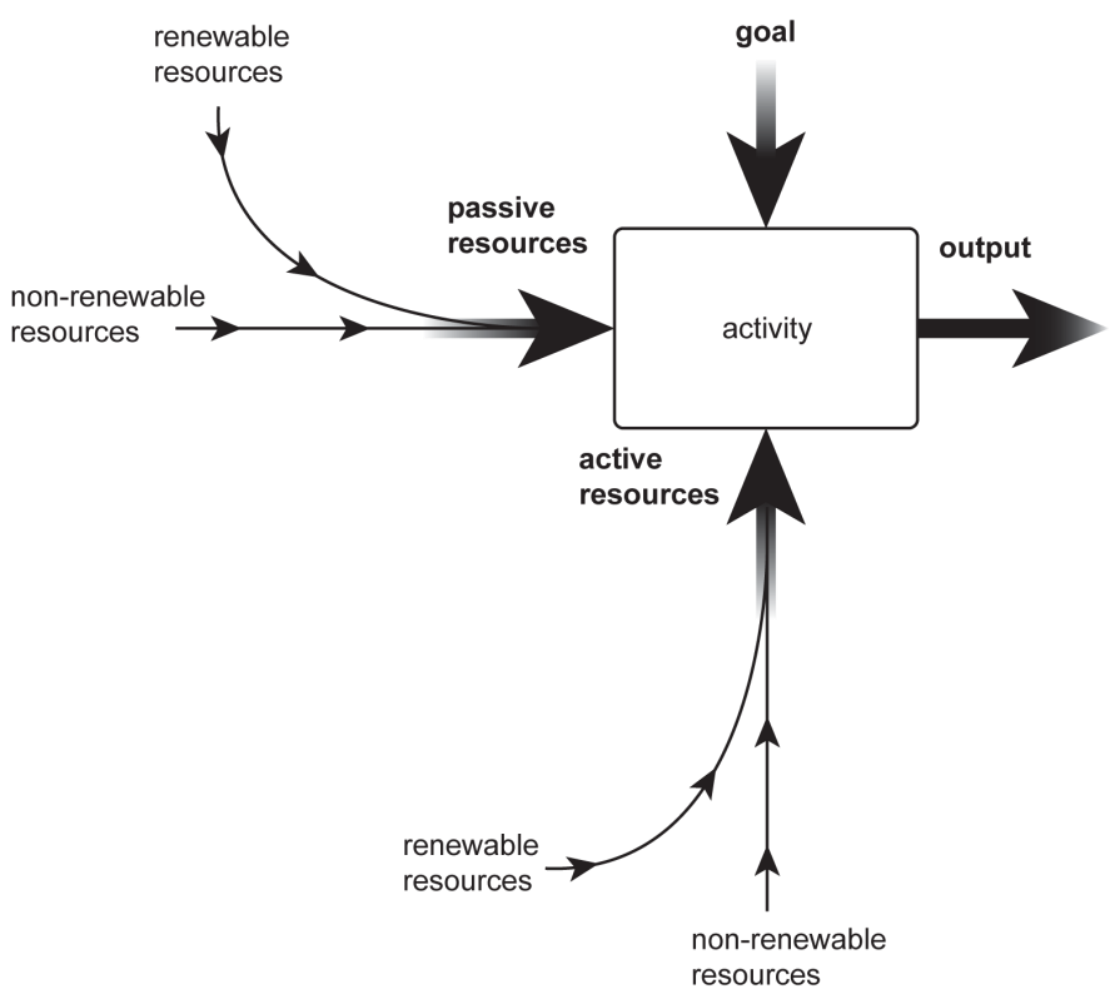

Fig 2. An activity operating within the Earth system, where active renewable and non-renewable resources originating in the system use passive renewable and non-renewable resources, also originating in the system. The arrows indicate the direction of flow of material and/or cognitive entities. 
The output of the activity shown in Figure 2 may be broken down into three kinds of components: intended yield, intended resources, and waste, as discussed below.

\section{Yield production by activities:}

The activity may produce components that are intended to be yielded to the wider system. These components may either contribute to resource stocks in the system, or they may be used directly as passive and/or active resources in other activities within the system (Brown and Ulgiati 1997; Campbell and Garmestani 2012; Ekins 2011; Liao et al. 2011). They are represented in Figure 3 as intended yield. For example, agricultural activity may produce outputs such as meat and vegetables as yield to be used by humans in the activities of cooking and eating (Kajikawa 2008; Metcalf and Widener 2011).

Resource production by activities:

The activity may also produce components intended to be used as passive and/or active resources in the activity itself (Costanza and Daly 1992; Ekins 2011). These are represented in Figure 3 as intended resources. For example, economic activity generates goods and services as an output, a portion of which are intended for use as resources in economic activity itself to produce further goods and services (Ekins 2011; Eurostat 2010; Eurostat 2011a). It should be noted that certain parts of the intended resource stream may conventionally be considered to constitute waste, but are instead to be utilised in the activity as a resource (Marchettini et al. 2007; Yang et al. 2003; Zhang et al. 2011). The term "waste" is used here in a sense slightly modified to that offered by the OED: The by-products of an activity that have no utility to the activity (OED 2012). For example, used cooking oil may from certain perspectives be viewed as waste in relation to the activity of cooking food. However, in order to reduce the environmental impact of cooking food, this oil may be used in the activity as a biofuel (i.e. passive resource) to provide the energy required to heat the food.

\section{Waste production by activities:}

In addition to intended resources and yield, the activity may produce components that can be considered to be waste in relation to the activity (Barles 2010; Brown and Ulgiati 1997; Marchettini et al. 2007; Rosen et al. 2008; Zhang et al. 2011), as shown in Figure 3 below. That is, the fraction of the activity's output that is intended neither as yield nor resources and as such, has no utility in relation to the activity (OED 2012). For example, agricultural activity may produce greenhouse gases due to the use of fossil fuels as passive resources, which have no utility in relation to the activity itself and are not intended for use by other activities on Earth (Walter and Stützel, 2009). However, the 
terms "resource" and "waste" are defined here in relation to the activity under study. As such, components that may be classed as waste in relation to one activity may in fact represent resources to a different activity operating within the Earth system (Marchettini et al. 2007; Raut et al. 2011; Zhang et al. 2011). For example, an empty plastic bottle may be considered as waste in relation to the activity of drinking bottled water, but a passive resource in relation to the activity of recycling plastic.

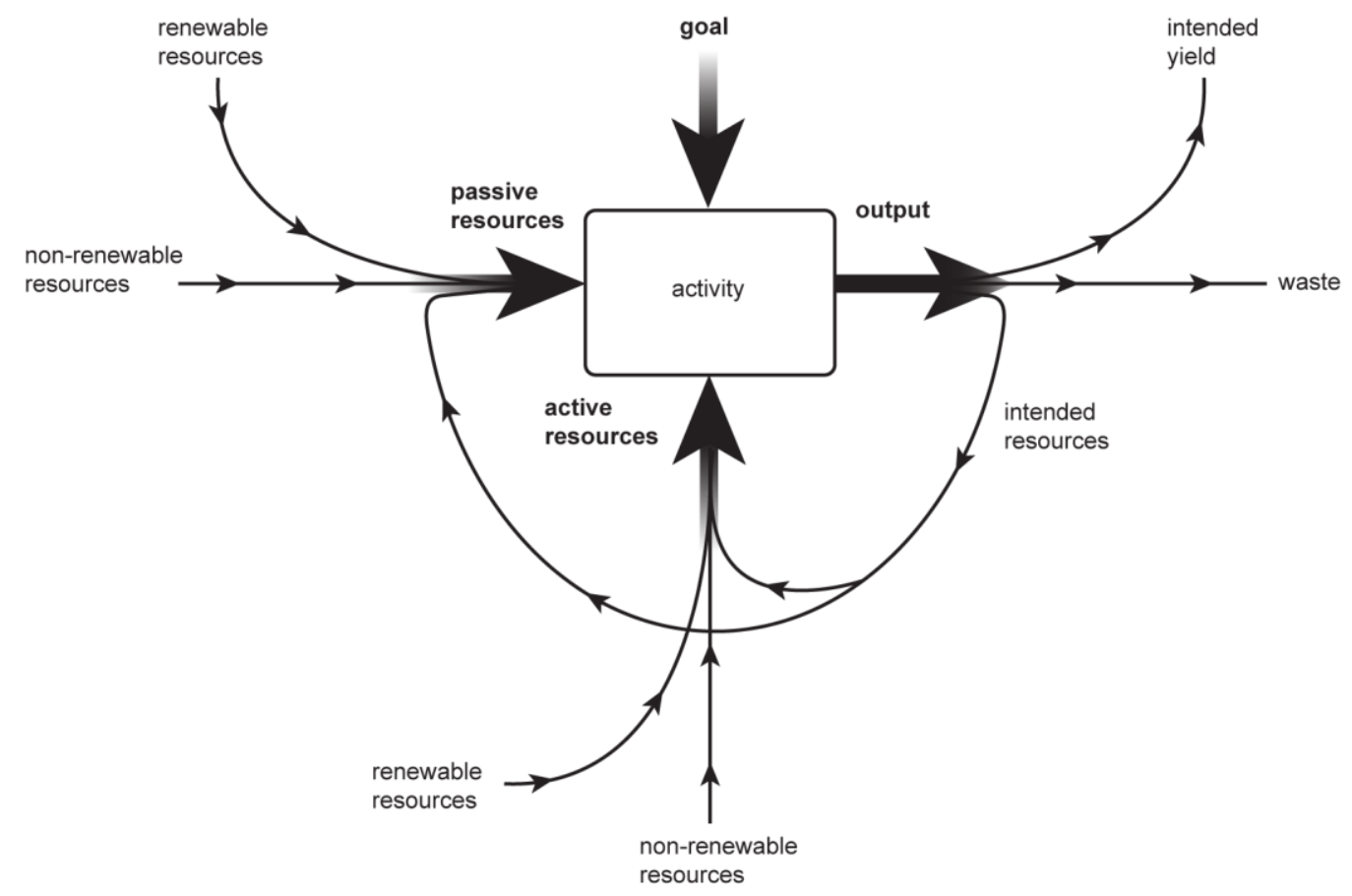

Fig 3. An activity operating within the Earth system, where active renewable and non-renewable resources use passive renewable and non-renewable resources to produce yield, resources, and waste within the system. The arrows indicate the direction of flow of material and/or cognitive entities.

Note that in the above paragraphs, we have focused primarily on physical examples of resources, yield, and waste. However, it should be noted that since the medium being transformed is MEI (Blanchard and Fabrycky, 1981), the labels of renewable and nonrenewable passive and active resources, intended resources, intended yield, and waste may equally be applied to intangible, information-based entities such as knowledge, values, social norms, policies, etc.

\subsection{Sustainability as an emergent property}

As discussed previously, in order to sustain entities valued by humans, we need to ensure the sustainability of the activities that produce these entities in the first place. That is, their ability to continue operating within the system. As an ability, sustainability may be viewed as a property of an entity that is manifested as behaviour that produces the effect of maintenance/continuation (Wang et al., 2008), either of the entity in question or some other target (discussed in Section 2.2). In Section 4.1, it was 
shown that the sustainability of an activity in the Earth system may be considered to be manifested as behaviour that is conducive to the activity's continued operation within the system. From this perspective, we may consider sustainability to be a property of an activity operating within the Earth system.

In Section 4.1, it was shown that a range of different activities form the foci of human efforts towards sustainability. Thus, humans are ultimately concerned with the sustainability of multiple activities in the Earth system, as opposed to one activity in particular. In Section 4.2, we illustrated the basic behaviour of activities operating within the Earth system by focusing on the behaviour of a single activity in isolation. However, as discussed in Section 4.2, certain outputs produced by one activity in the system may be used as resources by other activities in the system. In other words, activities in the Earth system may be coupled (Hubka and Eder, 1988; Turner, 2010; Yin and Xiang, 2009). Activities may be coupled in at least three ways, as shown in Figure 4 below.

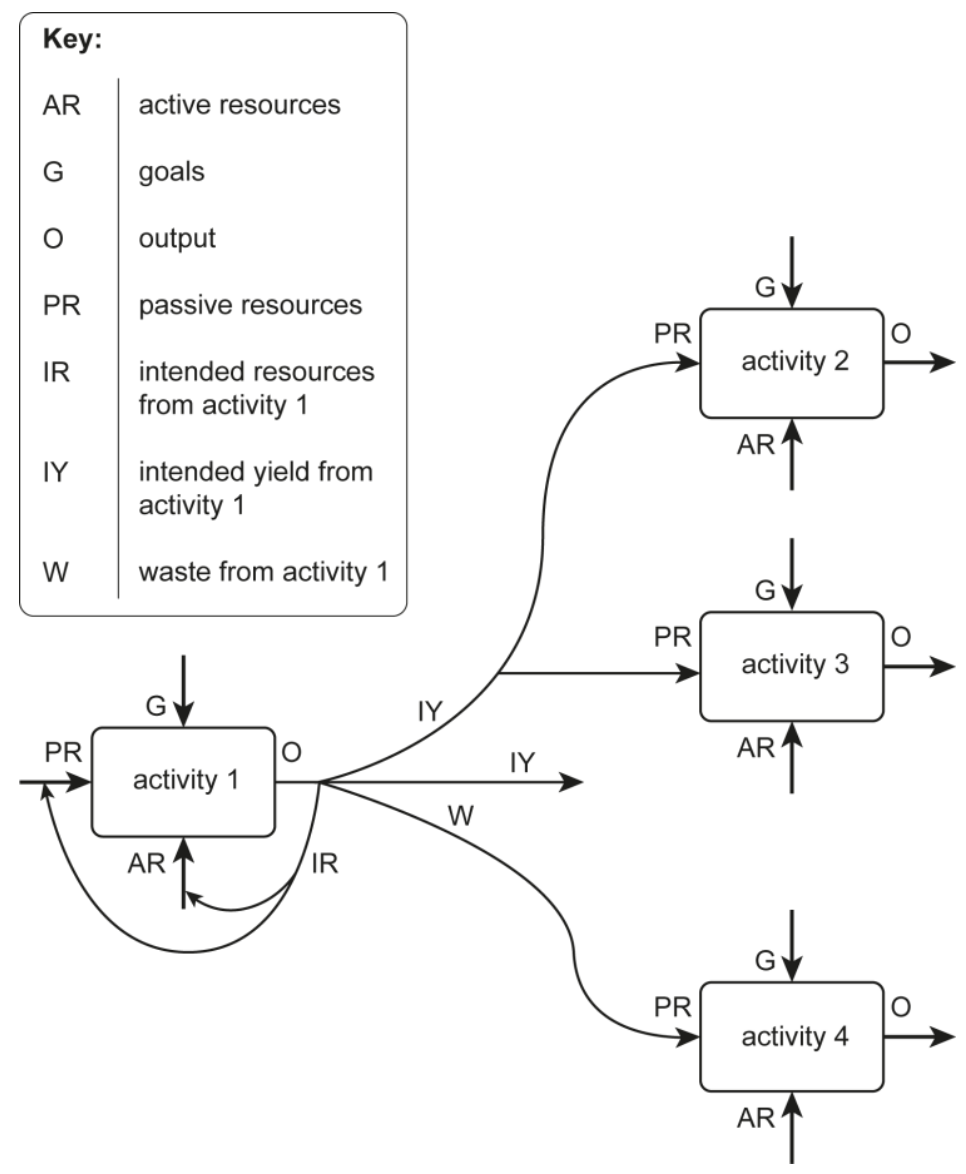

Fig 4. Multiple activities operating in the Earth system, linked by three kinds of coupling relationship: feedback (represented by the flow of intended resources); connection in series (represented by the flow of waste); and connection in parallel (represented by the flow of intended yield). 
Firstly, as discussed in Section 4.2, an activity may produce its own passive and active resources. In such a case, it may be said that the activity displays feedback - that is, part of its output (i.e. intended resources) is used as part of its input (i.e. passive and active resources) (Hubka and Eder, 1988). In short, the activity is coupled with itself. For example, in Figure 4, it may be seen that activity 1 displays feedback, represented by the flow of intended resources. Secondly, as discussed in Section 4.2, the yield or waste produced by one activity may be used as a passive or active resource by another activity in the system. In such a case, it may be said that the two activities are connected in series (Hubka and Eder, 1988). For instance, in Figure 4, it may be seen that the intended yield produced by activity 1 is used as a passive resource by activities 2 and 3 . Thus, activity 1 is connected in series with both activities 2 and 3. Further, the waste produced by activity 1 is used as a passive resource by activity 4 . Therefore, activity 1 is also connected in series with activity 4. Finally, an activity in the Earth system may share its input of passive or active resources with another activity in the system. In this case, it may be said that the activities are connected in parallel (Hubka and Eder, 1988). For example, in Figure 4, it may be seen that activities 2 and 3 share an input of passive resources originating from the output of activity 1 and thus, are connected in parallel.

According to O'Donnell and Duffy (2005, p.57), a goal may be viewed as referring to "a future situation, which is perceived by the goal originator to be more desirable than the current situation." Given that activities are "goal-directed," it may be seen that humans can influence their behaviour towards what is required for sustainability by formulating and implementing certain activity goals (Eurostat, 2011; Parris and Kates, 2003; Quental et al., 2011). These may be termed "sustainability goals" (Ness et al., 2007, p.498). Owing to the relationships outlined above, sustainability goals implemented to influence the behaviour of one activity in the Earth system may have an indirect impact on the behaviour of other activities to which the activity in question is connected. With respect to sustainability, this impact may not necessarily be a positive one - the kind of behaviour that is conducive to the continued operation of one activity in the Earth system may in fact be detrimental to the sustainability of other activities in the system (Alfaris et al., 2010; Voinov, 2007). For example, consider activities 1 and 4 in Figure 4 above. We may set a sustainability goal for activity 1 , focused on reducing the waste produced by the activity (more on sustainability goals in Section 5.1). However, it may be seen that activity 4 relies upon the waste output from activity 1 as a passive resource. As discussed in Section 4.1, an activity fundamentally depends upon resources for its continued operation. Thus, reducing the waste output of activity 1 may compromise the sustainability of activity 4 , by reducing the availability of the passive resources it is dependent upon.

From the above, it may be seen that when seeking the sustainability of multiple activities in the Earth system, formulating and implementing sustainability goals for each activity in isolation is unlikely to be effective in bringing about the required 
behaviour. That is, behaviour that is conducive to the continued operation of the activities collectively. The relationships among the activities must also be taken into account when formulating the goals. As discussed in Section 3.1, the structure of a system refers to "what its components are, how they are connected, and what passes across those connections" (Tully, 1993, p.46). Following on from this, Hubka and Eder (1988, pp.255-257) suggest that we may view the structure of a system from two different perspectives: (i) its component structure, i.e. "structure consisting of components and their relationships" as described above; and (ii) its function structure, i.e. "structure consisting of functions and their relationships, [...] structure of activities." If we consider that a particular set of interconnected activities within the Earth system can be partitioned as a sub-system, then it may be seen that sustainability can be described as an emergent property of a particular system of interest (Bodini, 2012; Godfrey, 2010; Wahl and Baxter, 2008). That is, a property that is "not determined solely from the properties of the system's parts, but which is additionally determined by the system's structure (i.e., by the way the parts are connected to form the system)" (Thomé, 1993, p.7). Even if all activities in a system may be said to have the property of sustainability individually, there is no guarantee that the system as a whole also has this property.

As discussed in Section 4.1, the sustainability of an activity in the Earth system may be considered to be manifested as behaviour that is conducive to the activity's continued operation within the system. In turn, the sustainability of a system may be considered to be manifested as behaviour that is conducive to the continued operation of the system as a whole within its wider environment. In Section 3.1, it was shown that system behaviour per se may be viewed as an emergent property (Tully, 1993). Thus, for sustainability to emerge in a system, the behaviour of individual activities within the system must contribute to the kind of system behaviour described above. As such, it may be seen that to successfully shift a system toward the behaviour required for sustainability, it is possible that certain activities in the system may have to cease operation. For example, certain authors suggest that in order to achieve sustainability of the global economic system within the Earth system, the activity of economic growth needs to be halted (Daly, 1990).

In the literature, sustainability may be described as an emergent property of the whole Earth system, including human society as an integral part. For example, Wahl and Baxter (2008, p. 73) remark that sustainability may be viewed as an emergent property of "the complex dynamic system that contains culture and nature." As shown in Section 3.2, a range of different sub-systems of the Earth system are considered in human efforts towards sustainability. Accordingly, sustainability may also be positioned as an emergent property of sub-systems of the Earth system. In this vein, Bodini (2012, p. 140) describes sustainability as "an overall attribute that emerges from the internal processes that characterize human-environmental systems." In the context of the built 
environment, Godfrey (2010, p.219) suggests that sustainability "may be seen as an emergent property of the complex systems involved."

The emergent nature of sustainability in the Earth system and its sub-systems may be problematic for humans. As shown above, when seeking sustainability in a system, knowledge on the relationships between the activities in the system is required when formulating sustainability goals. However, in certain cases, it may be difficult for humans to decipher these relationships (Komiyama and Takeuchi, 2006; Quental et al., 2010). Bodini (2012, p. 140) suggests that in large-scale economic, social, and environmental systems, relationships reach such a high degree of complexity that "our perception of cause and effects is confounded." As a result, it may be difficult to predict the impact that sustainability goals will actually have on the behaviour of individual activities and in turn, the system of interest as a whole.

In summary, we may view sustainability as a property from two perspectives:

i. A property of an individual activity in a system, manifested as behaviour that is conducive to the activity's continued operation within the system. That is, the ability of an activity to continue to operate within a system.

ii. An emergent property of a particular system of interest, manifested as behaviour that is conducive to the continued operation of the system as a whole within its environment. That is, the ability of a system to continue operating within its environment. In order for sustainability to emerge in a system, the behaviour of all activities in the system must contribute to this kind of system behaviour (given that system behaviour per se may be viewed as an emergent property (Tully, 1993)).

As discussed above, humans may influence the behaviour of activities in the Earth system and its sub-systems towards what is required for sustainability by implementing sustainability goals (Ness et al., 2007; 0’Donnell and Duffy, 2005). A goal refers to a future situation that is considered to be more desirable than the current one, and may be viewed as a component of human knowledge (O'Donnell and Duffy, 2005). Thus, it may be seen that in formulating sustainability goals for activities in the Earth system and its sub-systems, humans are interpreting their current behaviour to produce knowledge on how they should behave with respect to sustainability in the system of interest (Derissen et al., 2011). In this vein, the production and use of knowledge in human effots towards sustainability is examined in Section 5.

\section{Sustainability knowledge}


As discussed in Section 1, knowledge may be viewed as a driver of human action, both generally and in efforts towards sustainability. For example, Newell (1982, p.100) describes knowledge generally as "a potential for generating action." In a similar vein, Meadows (1998, p.3) positions knowledge of "the discrepancy between the desired state or goal and the perceived state of [a] system" as a driver of human action towards sustainability. In the following sections, we examine key components of knowledge involved in human action towards sustainability. Note that throughout, we employ the term "knowledge" in a broad sense to include "expert knowledge," but also less concrete elements such as "implicit theories on how the physical world behaves," "outcome foci," "experiences," (Reber, 2011) and also perceptions (Gero and Kannengiesser, 2004).

As discussed in Section 4.3, humans may influence the behaviour of activities in a system towards what is required for sustainability by implementing sustainability goals (Eurostat, 2011; Parris and Kates, 2003; Quental et al., 2011). Sustainability goals, like all goals, refer to a future situation that is considered to be more desirable than the current one (O'Donnell and Duffy, 2005), and may be viewed as key components of knowledge involved in efforts towards sustainability. As discussed in Section 5.1 below, sustainability goals are formulated on the basis of how humans perceive the behaviour of an activity, i.e. knowledge on current behaviour. Humans take action to implement goals and bring about a shift in behaviour on the basis of these two components of knowledge.

In addition to formulating and implementing sustainability goals, it is clearly also necessary to determine whether or not they are being fulfilled (Derissen et al., 2011; Eurostat, 2011a; Ness et al., 2007; van Zeijl-Rozema and Martens, 2010). To do so, humans need knowledge on the behaviour of activities in relation to sustainability goals, after the goals have been implemented (Jordan et al., 2010; van Zeijl-Rozema and Martens, 2010). As we will show in Section 5.2 below, the process of sustainability assessment (SA) may be viewed as the primary means by which humans gain such knowledge. Humans define or select indicators to assess the behaviour of an activity in relation to its sustainability goals, and then evaluate these indicators to gain knowledge on actual behaviour. Measures may also be selected to provide a holistic view on the behaviour of systems from the perspective of sustainability.

\subsection{Sustainability goals}

As discussed above, sustainability goals, like all goals, refer to a future situation that is considered to be more desirable than the current one. They may be viewed as components of knowledge, describing how an activity should behave with respect to sustainability in a particular system of interest (Ness et al., 2007; O'Donnell and Duffy, 2005). In order to formulate sustainability goals for an activity in a system, humans must interpret its current behaviour (Jordan et al., 2010; Walter and Stützel, 2009). In 
Section 4.2, it was shown that the use and production of resources, the production of yield, and the production of waste may be viewed as basic aspects of the behaviour of activities operating in the Earth system. Humans may interpret these aspects of a particular activity's behaviour, to produce knowledge on current behaviour and to formulate sustainability goals for the activity (Eurostat, 2011a; Meadows, 1998; Parris and Kates, 2003; Walter and Stützel, 2009). On the basis of what they know about the activity's behaviour, humans can suggest actions to be taken with respect to the system components involved in the activity, that are expected to result in the activity fulfilling its sustainability goals. To actually implement the goals, humans then carry out these actions (Eurostat, 2011a; Parris and Kates, 2003). For instance, if humans formulate the goal of "minimise fossil fuel consumption" for agricultural activity within a farming system, they may take action to allocate alternative renewable passive resources to the activity so that it fulfils the goal.

As an example, the work of Daly (1990) may be seen to point to a number of sustainability goals. The goals focus on resource use and waste production, and are intended to influence the behaviour of human activity generally towards sustainability in the Earth system. Firstly, Daly suggests that non-renewable resources "cannot be maintained intact short of nonuse." That is, since they are not believed to be regenerated significantly along anthropological timescales of thousands of years (Daly, 1992), depletion of non-renewable resource stocks may be considered to be irreversible as shown in case (a) in Figure 5. Given that like all activities, human activities depend fundamentally upon resources for their continued operation (discussed in Section 4.1), they should not use non-renewable resources. The eventual total depletion of nonrenewable resource stocks would compromise the sustainability of human activity generally in the Earth system. To implement this goal (in highly simplified terms), humans may allocate renewable resources to their activities to replace any nonrenewable resources that are currently used.

With respect to renewable resources, Daly (1990a, p. 2) argues that "harvest rates should equal regeneration rates." In other words, using renewable resources faster than stocks are regenerated may lead to depletion of renewable resource stocks (Campbell and Garmestani, 2012), as shown in case (b) in Figure 5. Again, because of human activities' reliance upon resources for their continued operation, they should use renewable resources at rates equal to or less than the regeneration rate of resource stocks to avoid depletion, as illlustrated in cases (c) and (d) in Figure 5 respectively. To implement this goal (again, in highly simplified terms), humans may take action to reduce the rate at which their activities consume renewable resources. Note that in addition to consuming renewable resources, it is also activities (both anthropogenic and natural) that regenerate the stocks of such resources in the Earth system. As shown in Section 4.2, activities produce yield, i.e. useful components that are intended to be yielded to the wider system. These components may be used directly as resources in 
other activities within the system, or they may contribute to resource stocks in the system (Brown and Ulgiati 1997; Campbell and Garmestani 2012; Ekins 2011; Liao et al. 2011).

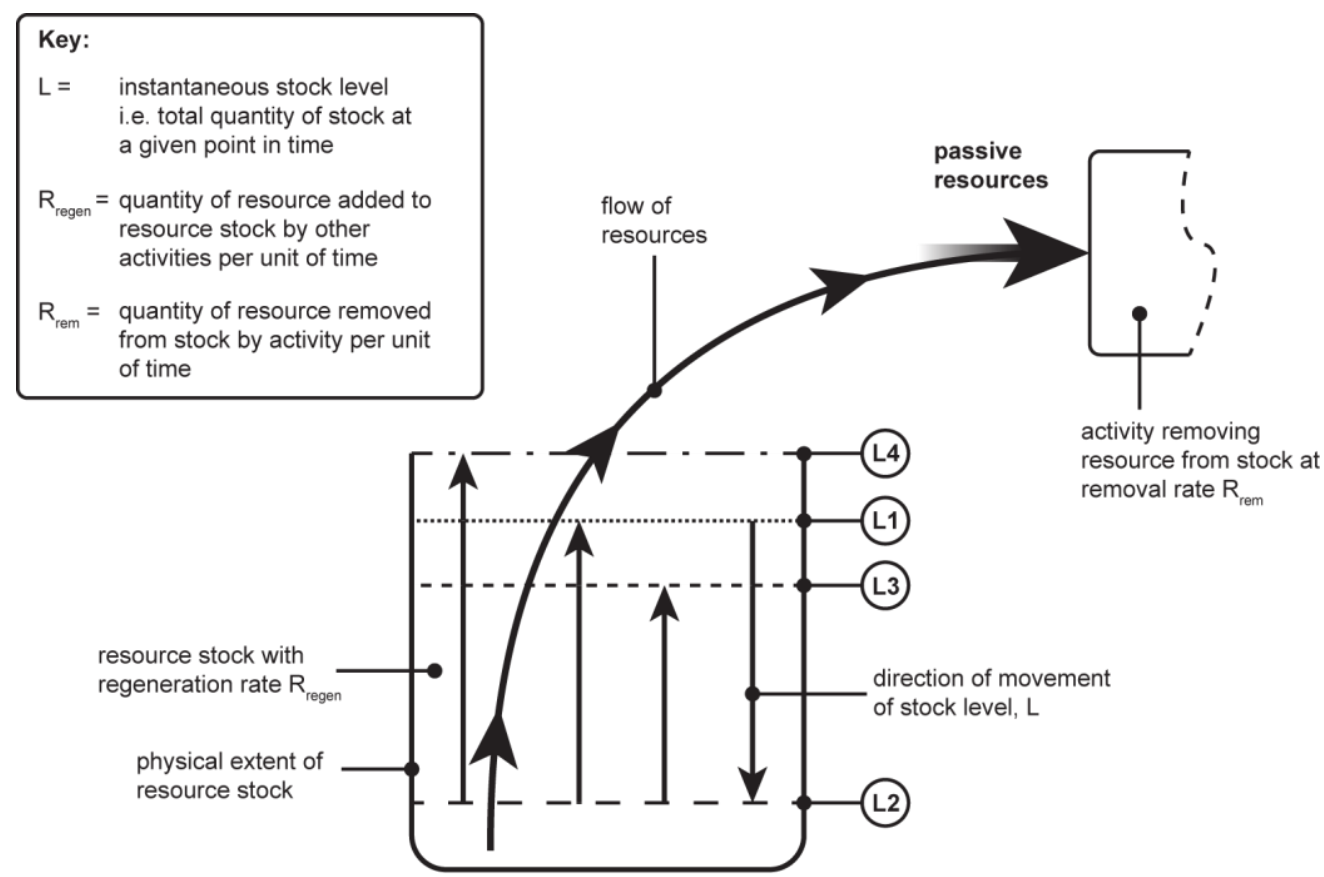

(a) Non-renewable resource depletion:

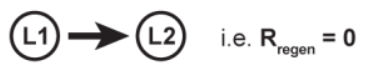

(b) Renewable resource depletion:

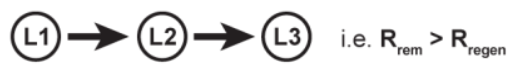

(c) Renewable resource maintenance:

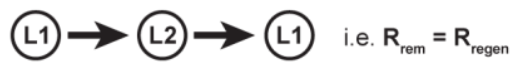

(d) Renewable resource generation:

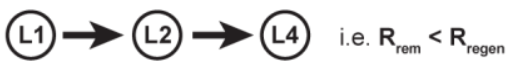

Fig 5. An activity removing resources at removal rate $\mathrm{R}_{\text {rem }}$ from a physical stock with regeneration rate $R_{\text {regen. }}$ Depending on the relative magnitudes of $R_{\text {rem }}$ and $R_{r e g e n}$, the stock will be depleted, maintained, or increased.

Finally, with respect to waste production, Daly (1990a, p. 2) writes that for sustainability, "waste emission rates should equal the natural assimilative capacities of the ecosystems into which the wastes are emitted." Emitting more waste than can be processed within the Earth system at a given time may lead to accumulations of waste within the system, as shown in Figure 6. In other words, the Earth system may become polluted (Zhang et al., 2011). If waste accumulates in the Earth system, then in addition to resources, an activity may also draw in waste as an unintended input as shown in Figure 6. In turn, this may have some detrimental effect on the activity that compromises its ability to continue operating. 


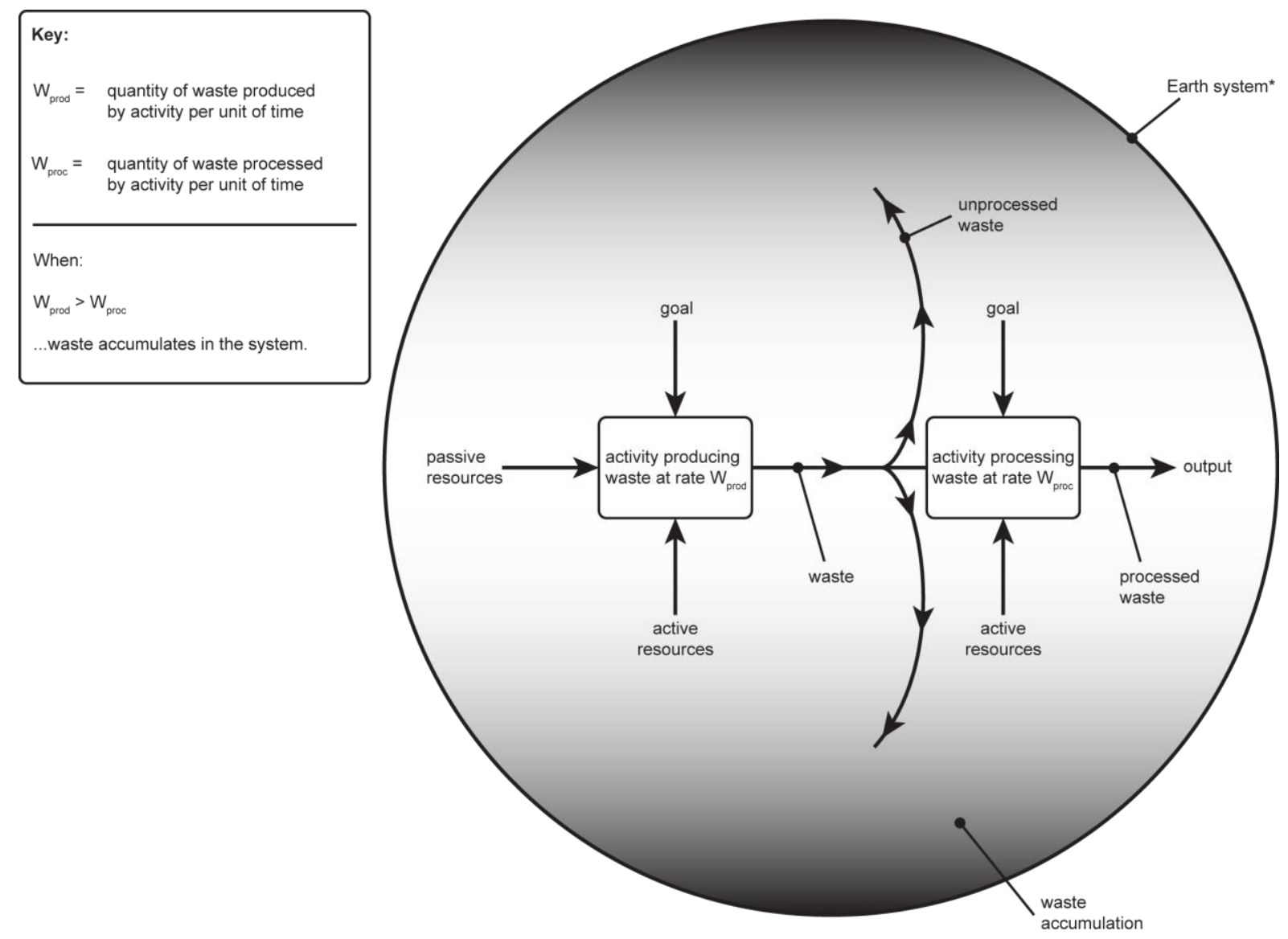

Fig 6. An activity producing waste within the Earth system, at rate $\mathrm{W}_{\text {prod, }}$, to be processed as a passive resource at rate $\mathrm{W}_{\text {proc }}$ by a different activity within the system. The arrows indicate the direction of flow of material and/or cognitive entities.

For example, the activity of driving a vehicle may produce waste gases that are noxious to humans. Collectively, these kinds of activities across society may produce noxious gases in excess of what can be processed in a timely fashion by natural activities. As a result, the gases are believed to accumulate in the air surrounding urban areas in the form of smog. In turn, human beings may unintentionally draw in these gases as an input to the activity of breathing. Since the gases are noxious to humans, this action may damage the lungs of the human being, which may be viewed as an active resource in the activity of breathing. If the lungs are damaged to a large enough extent, then the activity of breathing will cease to continue, i.e. the sustainability of the activity will be compromised. Given the potentially detrimental effects of excess waste on the sustainability of activities, human activities should produce waste at rates less than or equal to the rate that other activities in the Earth system can process it (given that waste in relation to one activity may be used as a resource in other activities as discussed in Section 4.2). To implement this goal (once again, in highly simplified terms), humans may take action to reduce the rate at which their activities produce waste. 
From the above example based on the work of Daly (1990), it may be seen that one set of considerations governing the formulation of sustainability goals is the physical laws and limits of the Earth system, e.g. the laws of thermodynamics, biological limits, and ecological limits. Walter and Stützel (2009, p. 1276) delineate sustainability goals for agriculture that may be seen to pertain to resource use, yield production, and waste production as highlighted in square brackets below. They write that "to be sustainable, agriculture must:

- supply humanity with food and fibre of sufficient quantity and quality [yield production goal];

- not endanger Earth's life support systems (such as the climate system and the functioning of ecosystems) or natural resources (including biotic and abiotic resources, soils and biodiversity) [resource use and waste production goals];

- allow producers to make a secure livelihood [yield production goal];

- contribute to rural development and the enhancement of rural communities;

- ensure the health of workers, rural populations and consumers;

- be equitable, just and produce in a socially accepted way."

These goals may be seen to highlight another aspect considered when formulating sustainability goals: the moral and social impacts of behaviour (Eurostat, 2011a; Parris and Kates, 2003). Voinov (2007, p.495) suggests that "sustainability is all about livelihood for humans as part of the ecosystem. We do not talk about sustainability of ecosystems in the absence of humans." From this perspective, it may be seen that humans strive for sustainability, but not at the expense of human society and wellbeing. Therefore, in formulating sustainability goals for activities, it is not sufficient to influence activity behaviour (outlined in Section 4.2) on the basis of the physical laws and limits of the Earth system alone. Additionally, the moral and social impacts of the resulting behaviour must be considered (Kajikawa, 2008). For example, we may influence the behaviour of agricultural activity so that it uses fewer non-renewable resources to produce yield for humans (e.g. food and materials), in order to ensure its continued operation in the Earth system. However, if this resulting behaviour involves the exploitation of humans through unpaid labour and excessive working hours, then according to the prevailing moral and social standards of numerous societies, it would likely be considered unacceptable (even if it is physically sustainable).

From the above, it may be seen that in addition to the physical laws and limits of the Earth system, the formulation of sustainability goals is also governed by the moral and social standards of humans. In Section 4.3, we suggested that in the context of activities and systems, sustainability may be viewed from two different perspectives: (i) the ability of an activity to continue operating within a system; and (ii) the ability of a particular system of interest to continue operating within its environment. However, it 
may now be seen that from a human perspective, it is not sufficient for an activity or system to simply "continue operating" - they must continue operating in a manner that is socially acceptable. In this vein, Vucetich and Nelson (2010, pp.539-540) suggest that sustainability can be either "virtuous" or "vulgar," depending upon the ethical standards of those seeking it. They argue that, "Progress in understanding and achieving sustainability requires addressing it as both a scientific and an ethical issue."

\subsection{Sustainability assessment}

As discussed in Section 4.1, humans may influence the behaviour of activities towards what is required for sustainability via sustainability goals (Eurostat, 2011; Parris and Kates, 2003; Quental et al., 2011). These are formulated on the basis of the (i) physical laws and limits of the Earth system (Daly, 1990), and (ii) moral and social standards of humans (Kajikawa, 2008; Walter and Stützel, 2009), as shown in Section 5.1. In turn, these goals are implemented by humans who suggest and then carry out actions that are expected to result in the activity fulfilling its goals (Eurostat, 2011a; Parris and Kates, 2003). After implementation, it is clearly necessary to ascertain whether or not the goals are being fulfilled. Given that sustainability is often a long term goal that we may never actually attain (as discussed in Section 2.2), it is at least necessary to monitor whether or not the activity in question is on track to fulfil its sustainability goals, i.e. whether its behaviour is moving in the desired direction. To do so, humans need to interpret its behaviour after sustainability goals have been implemented, to produce knowledge on how it behaves in relation to its goals (Jordan et al., 2010; van ZeijlRozema and Martens, 2010). In the context of sustainability, these efforts may be termed "sustainability assessment" (Bodini, 2012; Ness et al., 2007).

As shown in Section 5.1, sustainability goals focus on: (i) the use and production of resources, the production of yield, and the production of waste by activities within the physical constraints of the Earth system; and (ii) the moral and social impacts of this behaviour. Therefore, to assess an activity's behaviour in relation to sustainability goals, it is necessary to at the very least define measures that will provide a window on these aspects when evaluated (Wang et al., 2008). Along these lines, McCool and Stankey (2004, p.298) write of the need to link "specific measurable variables" to sustainability goals. Measures employed to evaluate behaviour in sustainability assessment may generally be referred to as sustainability indicators (SIs) (Ness et al. 2007; Jordan et al. 2010; Ramos and Caeiro 2010; Rametsteiner et al. 2011; van ZeijlRozema and Martens 2010; Singh et al. 2012). SIs need not necessarily be quantitative in nature. For instance, Meadows (1998, p.9) distinguishes between objective and subjective SIs. She writes that the former are those that are "sensed by instruments outside the individual - thermometers, voltmeters, counters, dials, rulers. They can be verified by others. They can be expressed in numbers." In contrast, she remarks that subjective SIs are those that "are sensed only within the individual by means that may 
not be easily explained and in units that are probably not numerical." In short: "Objective indicators primarily measure quantity. Subjective indicators primarily measure quality."

Analysing the range of indicators identifiable in the literature reveals that they may be broadly split into four categories, which are briefly delineated below. A categorisation of sustainability indicators and the approaches used to evaluate them is shown in Figure 7.

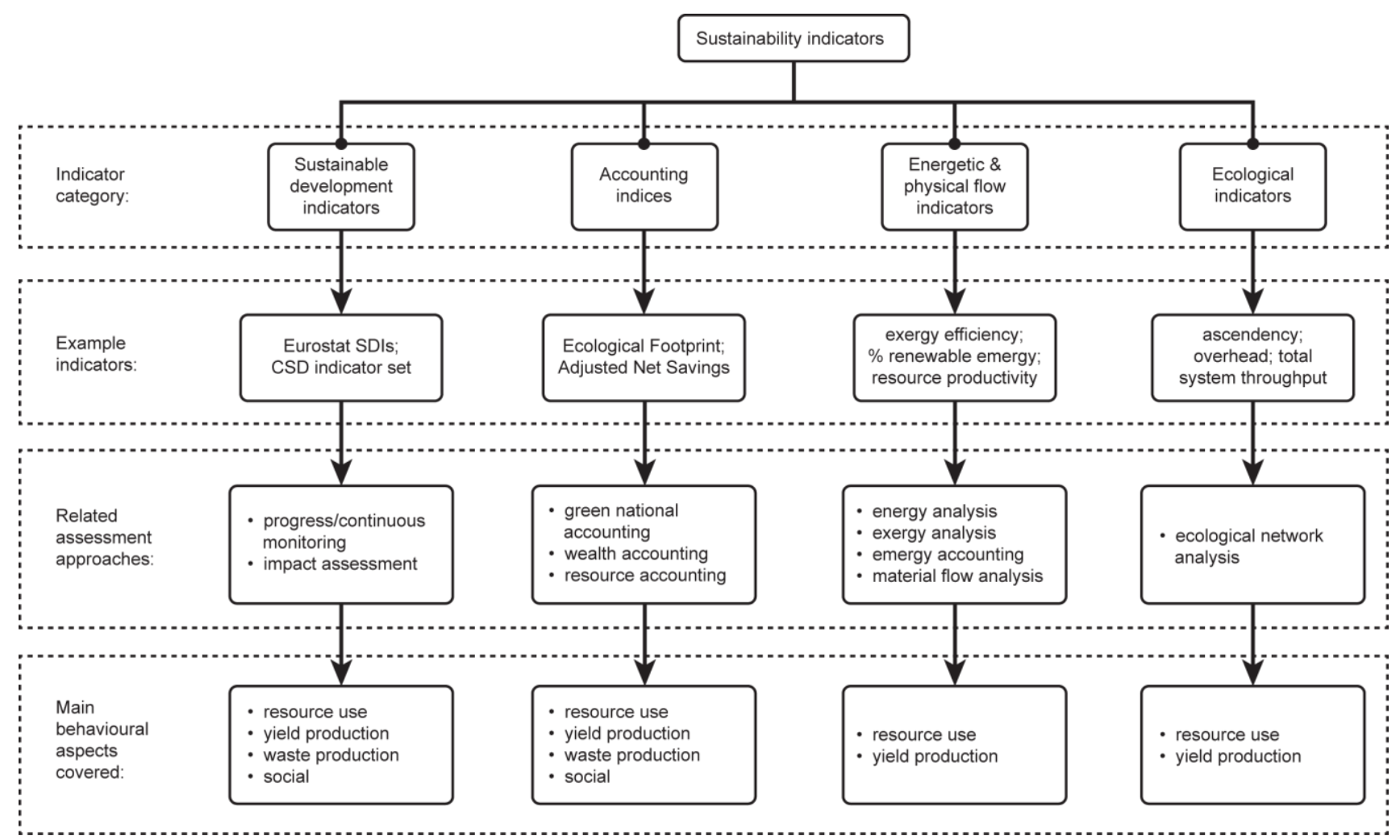

Fig 7. Hierarchy showing major categories of sustainability indicators identifiable in the literature, examples of specific indicators, assessment approaches associated with each category, and the main behavioural aspects covered by indicators in each category.

Hak et al. (2012, p. 46) suggest that although it is not possible to put an absolute figure on the number of indicators currently in use, "we can assume the existence of hundreds of various indices and sets of indicators or even several thousands of such metrics if individual indicators are included." As such, the categories provided below are not claimed to be exhaustive. Rather, based on the literature, they are intended to represent the indicator types most commonly encountered in sustainability assessment research:

- Accounting indices (AIs), which focus mainly upon the resource use, yield production, waste production, and social impacts of development and economic activities in the Earth system (Galli et al., 2012; Ness et al., 2007; Singh et al., 
2012). AIs are typically evaluated retrospectively through natural resource accounting (Galli et al., 2012), national wealth accounting (Alfsen and Greaker, 2007), and green national accounting (World Bank, 2010a) approaches.

Examples include the Ecological Footprint (Galli et al., 2012; Wackernagel and Yount, 1998), the Adjusted Net Savings index (World Bank 2010a), and the Genuine Progress Indicator (Posner and Costanza, 2011).

- Energetic and physical flow indicators (EPFIs), which focus mainly upon the resource use and yield production behaviour of production activities in the Earth system (Brown and Ulgiati, 1997), and the behaviour of production systems (Coppola et al., 2009; Liao et al., 2011) and regional systems (Campbell and Garmestani, 2012; Gasparatos et al., 2009a,b). EPFIs are typically evaluated retrospectively through energy analysis (Ertesvag, 2005; Liao et al., 2011), exergy analysis (Gasparatos et al., 2009b), emergy accounting (Campbell and Garmestani, 2012; Liu et al., 2012), and material flow analysis (Eurostat, 2011b; Ness et al., 2007) approaches. Examples include energy efficiency (Liao et al., 2011), exergy efficiency (Gasparatos et al., 2009b; Rosen et al., 2008), percent renewable emergy (Brown and Ulgiati, 1997; Campbell and Garmestani, 2012), and resource productivity (Eurostat, 2011a; Eurostat, 2011b).

- Sustainable development indicators (SDIs), focusing primarily upon the resource use, yield production, waste production, and social impacts of development activities in the Earth system (Eurostat, 2011a; Ness et al., 2007; Pülzl et al., 2011; Ramos and Caeiro, 2010). SDIs are typically evaluated retrospectively through progress monitoring (Eurostat, 2011a; van Zeijl-Rozema and Martens, 2010) and prospectively through impact assessment (European Commission, 2009; De Smedt, 2010) approaches. Examples include the Eurostat set of SDIs (Eurostat, 2011a), and the United Nations Commission on Sustainable Development's set of over one hundred Indicators of Sustainable Development (UN, 2007).

- Ecological indicators (EIs), which are holistic measures focusing upon the resource use and yield production behaviour of whole systems (Bodini, 2012; Ulanowicz et al., 2009). EIs are typically evaluated retrospectively through ecological network analysis (Bodini, 2012; Li and Yang, 2011). Examples include ascendency (Bodini, 2012; Li and Yang, 2011; Ulanowicz, 1980; Ulanowicz et al., 2009), total system throughput (Bodini, 2012; Ulanowicz, 1980; Ulanowicz et al., 2009), and overhead (Bodini, 2012; Ulanowicz, 1980; Ulanowicz et al., 2009).

Meadows (1998, p.10) highlights that, "When a system is extremely complex, it takes trial, error, and learning to produce a serviceable set of indicators." The definition and selection of SIs for activities in a particular system of interest is by no means an easy 
task. Firstly, there may be a range of potential SIs that could be used to assess the behaviour of an activity in relation to sustainability goals (Meadows, 1998). As such, Meadows (1998, p.9) highlights that the "very choice of an indicator is based upon some value, some inner human purpose that tells us what is important to measure." In turn, authors have emphasised the importance of involving multiple stakeholders in discussions on SIs (Celino and Concilio 2010; Garmendia and Stagl 2010; Robinson et al. 2011; Yang et al. 2011), including both expert stakeholders (e.g. natural scientists, sociologists, and engineers), and citizen stakeholders and their representatives (e.g. product users, local inhabitants, and politicians), to account for different values and perspectives (Pülzl et al. 2011; Rametsteiner et al. 2011). However, these differences mean that considerable negotiation may be involved in efforts to define or select SIs, which can be time consuming and fraught with intractable disagreements (Meadows, 1998).

Secondly, the choice of SIs may have an unintended and undesired impact on the behaviour of activities in a system. In this vein, Meadows $(1998$, p.3) remarks that, "When indicators are poorly chosen, they can cause serious malfunctions." For example, measures of $\mathrm{CO} 2$ emissions may be employed to assess the behaviour of businesses in relation to sustainability goals focused on reducing the level of $\mathrm{CO} 2$ produced (Eurostat, 2011a). Logically, the intention would seem to be that if we measure the amount of CO2 being emitted by businesses in relation to this goal, then businesses will reduce their CO2 emissions over time in order to meet the goal. However, certain decision makers react by offsetting their businesses' $\mathrm{CO} 2$ emissions. That is, rather than taking action to reduce their $\mathrm{CO} 2$ emissions, they take action to "cancel out" their $\mathrm{CO} 2$ emissions by, for example, planting extra trees to process $\mathrm{CO} 2$, or investing in carbon sequestration schemes (Norgaard, 2010). It may be argued that actually reducing the CO2 emitted is more desriable behaviour than offsetting with respect to sustainability (Norgaard, 2010). Measuring CO2 emissions seems like an obvious choice in relation to a goal to reduce the level of $\mathrm{CO} 2$ produced. Nonetheless, in doing so, we have created an unintended and arguably undesirable behaviour among businesses within the Earth system. Meadows (1998, p.10) remarks that there is "no shame in having a wrong model or a misleading indicator, only in clinging to it in the face of contradictory evidence." Thus, the process of defining and selecting SIs for activities in a system must be "evolutionary." The "necessary process is one of learning."

Sustainability assessment may be conducted at a range of scales, from local to global (Ness et al., 2007) as shown in Figure 8. Essentially, as we increase the scale of assessment from local to global, we are extending the boundary of the system of interest within which the behaviour of activities is interpreted (Ulgiati et al., 2011). For example, let us return to the context of agriculture, and consider the activity of crop production with a sustainability goal to "minimise non-renewable resource (NRR) consumption." At the local scale, we may assess only the direct inputs of NRRs required 
for operation of the activity, e.g. the inputs of petrol and oil for machinery. At the regional scale, however, we may additionally assess certain indirect inputs of NRRs to the activity, e.g. the NRRs that were consumed in extracting raw materials and converting them into petrol and oil for machinery. Finally, at the global scale, we may also assess the inputs to the activity directly from the biosphere (i.e. ecosystem services), e.g. the actual raw materials extracted from non-renewable stocks such as oil fields to produce petrol and oil (Ulgiati et al., 2011). With each increase in scale, the boundary of the system of interest is extended to include inputs originating from more activities and resource stocks than were considered at the previous scale. Thus, we may evaluate the same SI at different scales, and obtain different results. As such, Ulgiati et al. (2011, p.177) remark that the "value of a given indicator is only 'true' at the scale at which it is calculated." Furthermore, they highlight the importance of scale when interpreting the behaviour of an activity: "if a process evaluation is performed at a small scale, its actual performance may not be well understood and may be overestimated due to a lack of inclusion of some large-scale impacts."

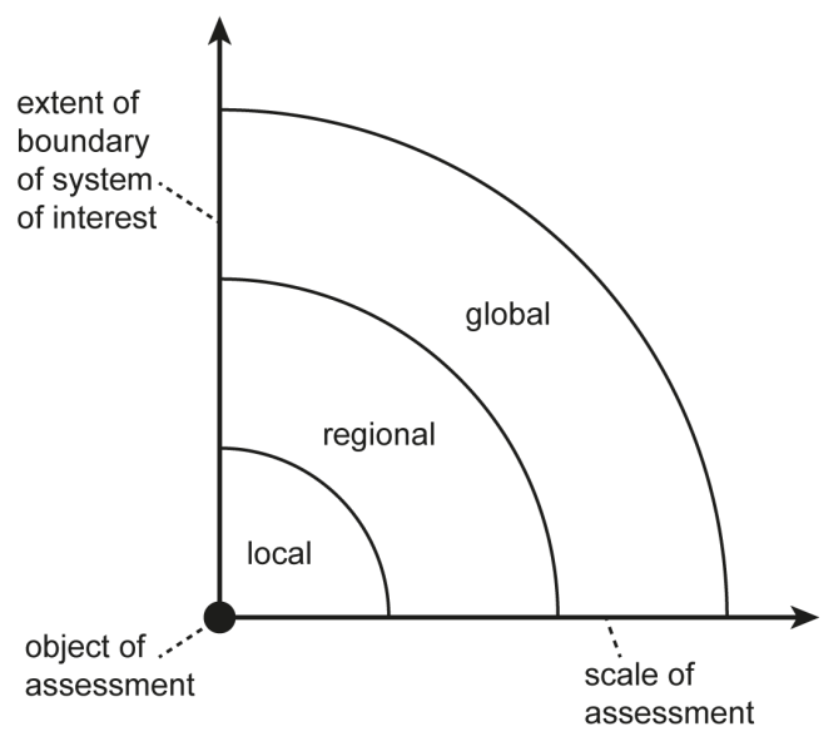

Fig 8. The varying spatial scale of sustainability assessment. The $x$-axis represents the scale of assessment, ranging from local, up to regional and global, whilst the y-axis represents the extent of the system of interest for the activity under study.

In addition to spatial scale, time is another factor that may infuence the way that activity behaviour is interpreted during sustainability assessment. For instance, Bell and Morse (2008, p. 16) highlight that from the perspective of sustainability, the behaviour of an entity may fluctuate considerably over long time periods. As such, depending upon the intervals at which this behaviour is assessed, "the interpretation of the trend [from the perspective of sustainability] in each block of time may be quite different" to one another, and to the interpretation of the behaviour of the system over multiple intervals 
i.e. in the longer term. They argue that the "choice of the starting point" or baseline for a sustainability assessment effort "can influence the results." As discussed in Section 2.3, sustainability is often a long term goal, that we may never be able to say that we have "attained". Rather, we may track our progress towards or away from it by continually assessing behaviour. As such, authors emphasise the need to adopt both long- and short-term perspectives in sustainability assessment (Ness et al., 2007). Assessment may be carried out retrospectively to produce knowledge on actual behaviour, or prospectively to produce knowledge on potential future behaviour (Ness et al. 2007; Rametsteiner et al. 2011). Given its future-oriented nature, the information obtained on behaviour through prospective sustainability assessment may be viewed as inherently uncertain (Upham et al., 2011). As such, authors comment on the need to acknowledge and manage uncertainty in prospective sustainability assessment (Benoît et al., 2009; De Lara and Martinet, 2009; Upham et al., 2011).

In summary, sustainability assessment consists of: (i) defining/selecting SIs to assess the behaviour of activities in a particular system of interest, in relation to their sustainability goals; and then (ii) evaluating these SIs to produce knowledge on the behaviour of the activities in question. Based on the above discussion, the overarching sustainability assessment process is represented graphically in Figure 9. Knowledge on behaviour obtained through the evaluation of SIs may be used in the execution of decisions relating to sustainability (Ness et al. 2007; De Smedt 2010; Heijungs et al. 2010; Ramos and Caeiro 2010; Rametsteiner et al. 2011; Singh et al. 2012), and thus be used to determine an appropriate course of action to be taken with respect to the sustainability of an activity or a whole system (Boyle et al., 2012). For instance, upon interpretation, the values obtained for a set of SIs selected to assess activities in a particular system of interest system may show that the activities are not on track to fulfil their sustainability goals. On the basis of this knowledge, humans may suggest and implement actions that are intended to shift the behaviour of the activities in the desired direction.

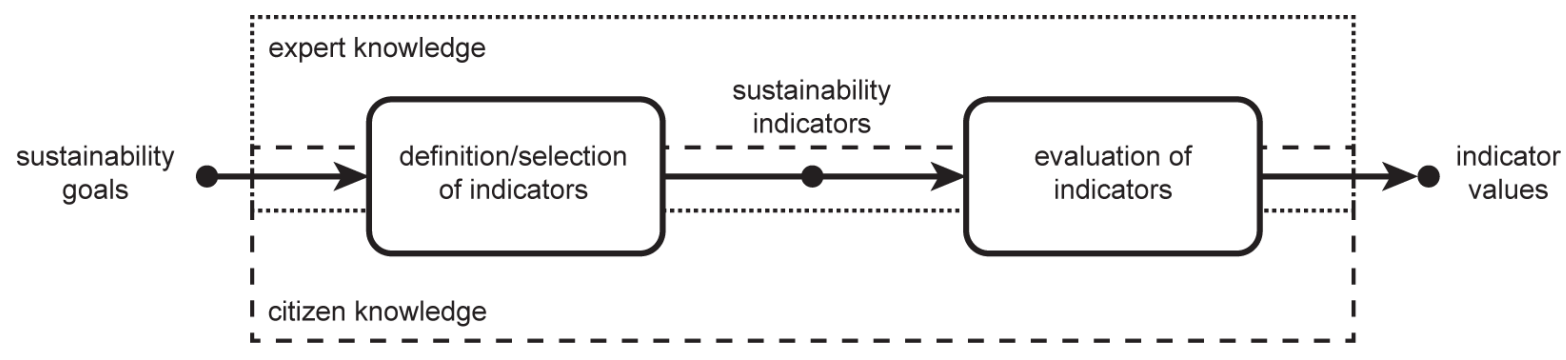

Fig 9. The sustainability assessment process, beginning with sustainability goals and consisting of the activities of: defining and selecting indicators, and evaluating indicators to obtain indicator values. The process may draw upon both expert and citizen knowledge throughout.

\section{The Sustainability Cycle and Loop}


As discussed in Section 1, the investigation documented in this paper aimed to develop models to explain the nature of sustainability in the Earth system, and how humans in different sectors may effectively strive for it. Three concepts initially emerged from the literature as significant for detailed investigation in relation to this aim:

- systems, as the context for human action towards sustainability;

- activities, as the most fundmental target that humans need to sustain within the Earth system; and

- knowledge, as the driver of human action towards sustainability.

The findings of a review of the sustainability literature from the perspective of the above three concepts were presented in Sections 3, 4, and 5. The corpus examined included sources from multiple sectors (outlined in Section 1), to gain a view that is as free from contextual nuances as possible. In Section 3, the Earth system was characterised as the ultimate context for human action towards sustainability, and different sub-systems of this overall system were discussed. In Section 4, the concept of an activity was defined in the context of the Earth system. It was shown that sustainability may be viewed either as a property of an individual activity in a system, or an emergent property of a particular system of interest. Humans may influence the behaviour of activities in a system towards what is required for sustainability by implementing activity sustainability goals. Finally, in Section 5, it was shown that humans formulate sustainability goals by interpreting the behaviour of activities in a particular system of interest. The formulation of these goals is goverened by (i) the physical laws and limits of the Earth system, and (ii) the moral and social standards of humans. The goals are implemented via actions that produce effects on the system components involved in the activities, resulting in a change in activity behaviour. To determine if the goals are being fulfilled or not, humans interpret activity behaviour after they have been implemented by defining and evaluating SIs.

In the following sections, we show how the findings of the literature investigation briefly summarised above were used to develop two models via a process of induction: (i) the Sustainability Cycle (S-Cycle), describing the operation of activities in a system from the perspective of sustainability; and (ii) the Sustainability Loop (S-Loop), describing a basic process that may lead humans towards sustainability. In Section 6.1, we develop the $S$-Cycle model on the basis of the literature on systems and activities covered in Sections 3 and 4. In Section 6.2, we introduce the S-Loop model. First, we highlight a basic process followed by humans striving for sustainability that emerges from the literature covered in Section 5. This may be described as an iterative process of interpretation and action, involving the concepts of systems, activities, and knowledge reviewed in Sections 3, 4, and 5. Next, we show that humans striving for sustainability may be considered to operate between two different "worlds": the external world, where activities and systems exist; and the interpreted world, where 
knowledge exists. We then develop the S-Loop model by describing the iterative process in the context of the external and interpreted worlds. Finally, in Section 6.3, we provide a brief demonstration of the models by applying them to a bioethanol production system described in the literature.

\subsection{The S-Cycle model}

As discussed throughout the paper, activities may be viewed as a fundamental target that humans need to sustain within the Earth system. In a system, activities may be viewed as "the fundamental elements that transform input to output" (O'Donnell and Duffy, 2005, p.56). For example, humans need production activities to transform raw materials into useful artefacts (Chapman, 2011), and socio-economic development activities to transform goods and services into intangible entities such as living standards and wellbeing (UNDP, 2011). We need certain natural activities to transform our waste products back into useful resources (Lindsey, 2011) such as water and

minerals. At the most fundamental level, we need biological activities to transform food into energy, and air into the oxygen we need to live. Thus, in order to sustain a particular entity, we need to sustain the activities that produce that entity within the Earth system.

Like all systems, the Earth system can be viewed as "an organized system of matter, energy, and information" (Skyttner, 1996, p.32). In Section 3.2, it was shown that this system may be approximated as a thermodynamically closed system (Daly 1992; Wackernagel and Rees 1997; Cabezas et al. 2005), whose primary external energy source is the Sun (Stremke et al., 2011) as shown in Figure 10 below. Processing MEI may be viewed as a basic function of the system (Bodini, 2012; Brown et al., 2004; Cabezas et al., 2005; Ulanowicz, 1980). The Earth system may also be described as a socio-ecological system, i.e. one where "society and nature are innately coupled" (Dawson et al., 2010, p.2844). Therefore, human beings themselves may be viewed as components of the system (Beddoe et al., 2009). As discussed in Section 4.2, the Earth system contains stocks of natural and artificial components (Costanza and Daly 1992; Ekins 2011; Williams and Millington 2004), that may be classed as either renewable or non-renewable in nature (Brown and Ulgiati 1997; Campbell and Garmestani 2012; Daly 1990), again shown in Figure 10. 


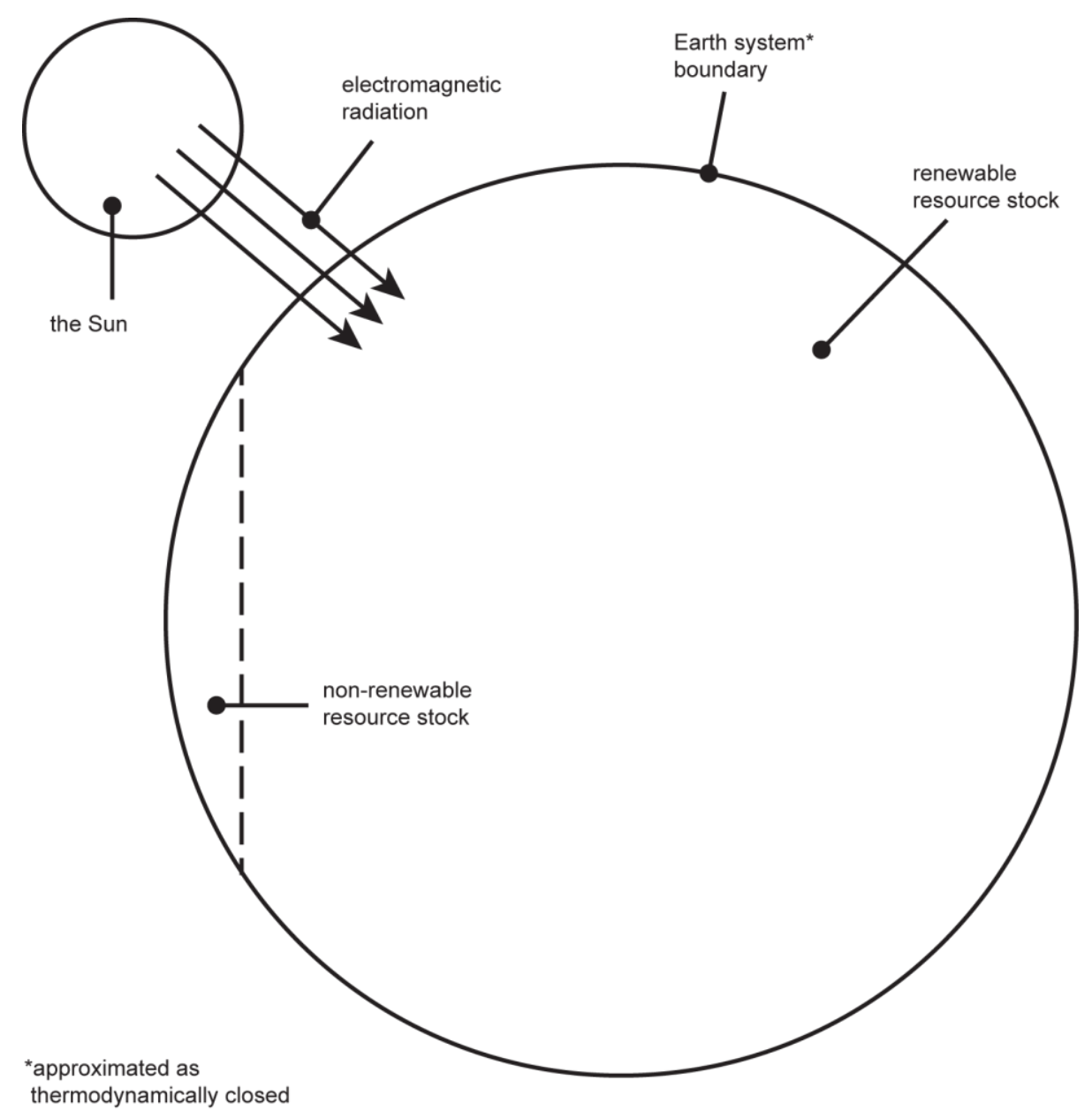

Fig 10. The Earth system, represented as a closed system whose primary external energy source is electromagnetic radiation from the Sun.

The S-Cycle model describes the operation of activities in the Earth system from the perspective of sustainability. The model is presented in Figure 11, and is described here in relation to the literature that it was induced from. In Section 4.2, it was shown that an activity can be defined as a goal-directed physical or cognitive action, where a set of passive resources are used by active resources to produce an output that should satisfy the goal of the activity (Boyle et al., 2009). Activities may use components from the renewable and non-renewable resource stocks in the system as passive and active resources, to produce an output consisting of three kinds of components, again shown in Figure 11: intended yield, i.e. components intended to be yielded to the wider system, that may be used directly as resources in other activities in the system, or may contribute to resource stocks in the system (Brown and Ulgiati 1997; Campbell and Garmestani 2012; Ekins 2011; Liao et al. 2011); intended resources, i.e. components intended to be used in the activity itself as passive and active resources (Costanza and Daly 1992; Ekins 2011); and waste, i.e. components that are intended neither as yield nor resources and thus, have no utility in relation to the activity (Barles 2010; Brown and Ulgiati 1997; Marchettini et al. 2007; Rosen et al. 2008; Zhang et al. 2011). Therefore, it may be seen that the sustainability of activities in the Earth system, i.e. 
their ability to continue to operate, depends fundamentally upon the availability of passive and active resources in the system. In turn, as discussed in Section 5.1, the availability of resources in the system depends upon the rate at which activities in the system consume and produce them. Consuming renewable resources faster than stocks are regenerated will lead to depletion of the stocks, and consuming non-renewable resources at any rate will deplete stocks since they are not regenerated significantly along anthropological timescales (Daly, 1990).
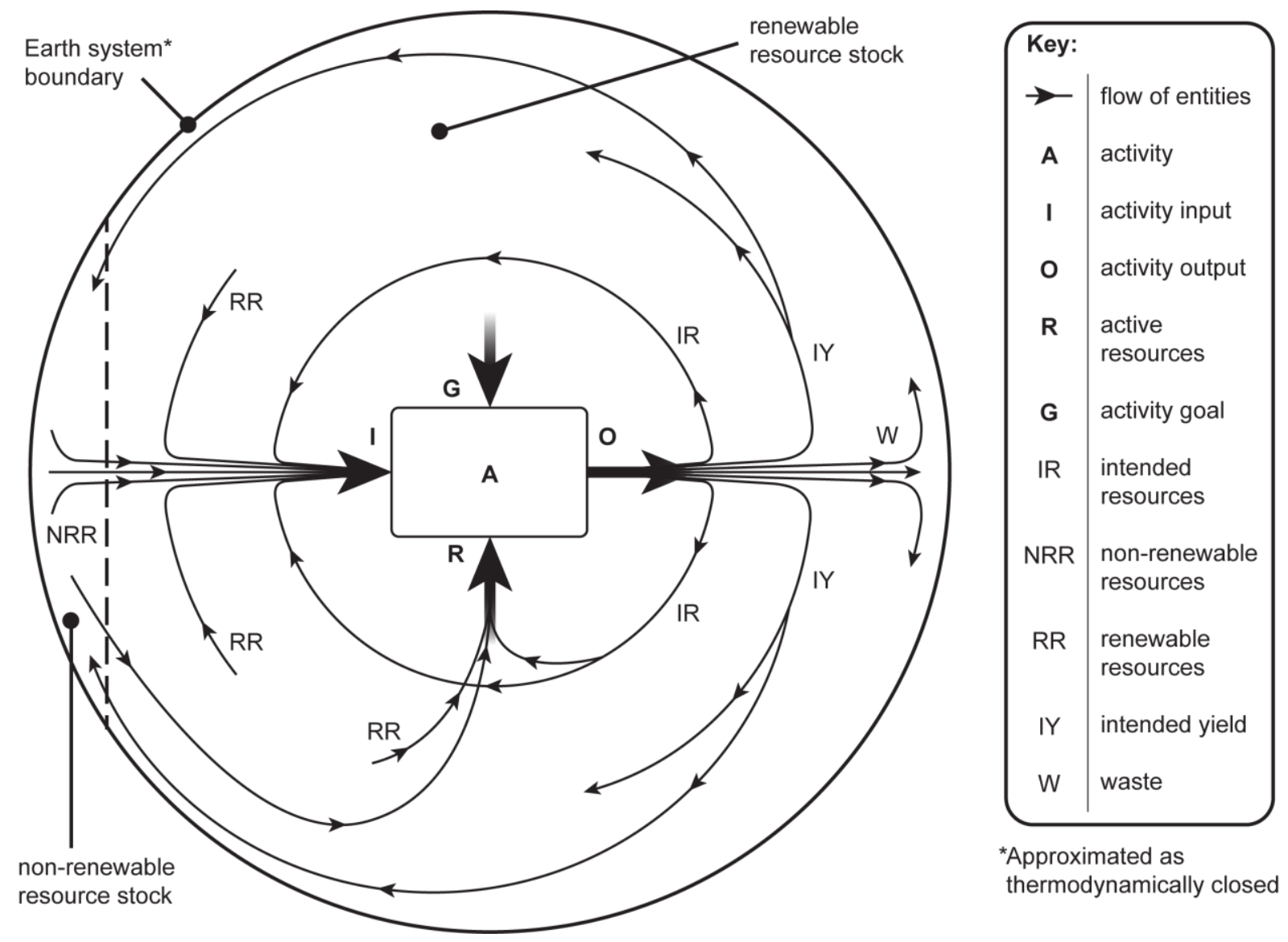

Fig 11. The Sustainability Cycle (S-Cycle) model, describing the operation of activities in a system from the perspective of sustainability.

In Section 4.3, it was shown that in addition to being viewed as a property of an individual activity in a system, sustainability may also be viewed as an emergent property of a particular system of interest (Bodini, 2012; Godfrey, 2010; Wahl and Baxter, 2008), i.e. a sub-system of the Earth system. For sustainability to emerge in a system, the behaviour of all activities in the system must contribute to the continued operation of the system within its environment (given that system behaviour per se may be viewed as an emergent property (Tully, 1993), as discussed in Section 3.1). These activities are likely to be coupled with one another, often in complex ways (Hubka and Eder, 1988; Turner, 2010; Yin and Xiang, 2009) as shown in Section 4.3. We may 
represent the total activity operating in a system in precisely the same way as we represent an individual activity (O'Donnell and Duffy, 2005), i.e. using the formalism first provided in Figure 1 in Section 4.1. Thus, the S-Cycle model presented in Figure 11 may be interpreted as describing the operation of an individual activity in the Earth system, or the total system activity, i.e. the aggregate of all natural and anthropogenic activities operating in the system at a given time.

The S-Cycle model may be used as a tool to support the analysis of activities in a particular system of interest from the perspective of sustainability, as will be demonstrated in Section 6.3. In Figure 11, the system boundary is represented as that of the whole Earth system. However, the S-Cycle model is generic - it describes the operation of activities in a system in completely general terms (e.g. it does not make reference to specific kinds of resources, yield, and waste, only the stocks and flows of these kinds of entities generally). Thus, we may represent the system boundary in Figure 11 as that of any particular system of interest within the Earth system. In short: we may apply the S-Cycle model to any system at any level. The location of the system boundary will determine the specific activities, stocks, and flows to be studied.

\subsection{The S-Loop model}

The S-Cycle model, introduced in Section 6.1, illustrates that the sustainability of activities in the Earth system depends fundamentally upon the availability of resources in the system. In turn, the availability of resources in the system depends upon the rate at which activities in the system consume and produce them. In Section 5, it was shown that humans may intervene in these dynamics by implementing sustainability goals to influence the behaviour of activities in a particular system of interest, and then assessing the resulting behaviour. Considering the literature covered in Section 5 holistically reveals a general process undertaken by humans striving for sustainability in different sectors, consisting of the following basic activities:

- interpret the behaviour of activities in a particular system of interest within the Earth system (Jordan et al., 2010; Walter and Stützel, 2009), to produce knowledge on their current behaviour, and how the activities should behave with respect to sustainability (Derissen et al., 2011) - that is, knowledge on sustainability goals (O’Donnell and Duffy, 2005);

- implement sustainability goals by suggesting and taking actions that produce effects on the system components involved in the activities, and are expected to result in the activities fulfilling their goals (Eurostat, 2011a; Parris and Kates, 2003); 
- determine if activities have fulfilled, or are on track to fulfil sustainability goals by assessing their behaviour after the goals have been implemented, to produce knowledge on that behaviour (Jordan et al., 2010; Ness et al., 2007; van ZeijlRozema and Martens, 2010); and

- $\quad$ on the basis of this knowledge, suggest and take actions regarding the sustainability of the activities and/or the system of interest as a whole (Ness et al. 2007; De Smedt 2010; Heijungs et al. 2010; Ramos and Caeiro 2010; Rametsteiner et al. 2011; Singh et al. 2012), e.g. if activities are not on track to fulfil their sustainability goals, humans may suggest and take actions to ensure that they are fulfilled in future, or they may begin the whole process again in the context of a different system, having learned from experience.

It may be seen that this process is essentially iterative: humans interpret the behaviour of activities in a system to produce knowledge, and then on the basis of this knowledge, take action to alter the behaviour of the activities and the overall system (given that system behaviour may be viewed as an emergent property, as discussed in Section 3.1). They then interpret the resulting behaviour to produce further knowledge and on the basis of this, suggest further actions to be taken. In other words: knowledge on behaviour determines the actions taken by humans striving for sustainability, and the actions taken by humans striving for sustainability result in the production of new knowledge on behaviour that determines further actions to be taken by humans, and so on and so forth.

According to Gero and Kannengiesser (2004, p.378), interpretation "transforms variables, which are sensed in the external world into the interpretations of sensory experiences, percepts and concepts that compose the interpreted world." They suggest that action may be viewed as "a transformation of an expected concept into an external representation." The result of action is "an effect, which brings about a change in the external world." Thus, it may be argued that humans striving for sustainability, via the iterative process of interpretation and action delineated above, operate between two different "worlds": (i) the external world, which may be viewed as the world "composed of representations outside" of a human (Gero and Kannengiesser, 2004, p.377) i.e. the world that is extrinsic to the human mind; and (ii) the interpreted world, which may be viewed as the world composed of "sensory experiences, percepts and concepts" (Gero and Kannengiesser, 2004, p.377) i.e. the inner mental world of a human. Clearly, different people may interpret representations in the external world in different ways and thus, the interpreted worlds of different people may be quite dissimilar in nature. As Meadows (1998, p.8) highlights, "people of different worldviews live literally in different worlds." This is arguably one of the reasons for the considerable variety in the targets we wish to sustain (Section 2), interpretations of sustainability (Section 2.1), sustainability goals (Section 5.1), and sustainability 
indicators (Section 5.2). In fact, it is worthwhile considering that the work reported in this paper represents the authors' interpretation of certain external representations, i.e. the sustainability literature. Other authors may have different interpretations of the same literature.

Above, Gero and Kannengiesser (2004) refer to both interpretation and action as the transforming of one thing into another. As highlighted throughout this paper, activities may be viewed as "the fundamental elements that transform input to output" (O'Donnell and Duffy, 2005, p.56). Therefore, it may be seen that both interpretation and action, as carried out in human efforts towards sustainability, may be viewed as activities, in precisely the same sense as the activities we are trying to maintain. For example, humans, as active resources, may undertake interpretation of an activity's behaviour with the goal of producing knowledge on that behaviour. They may use observations of behaviour as passive resources, to produce knowledge on behaviour as an output that satisfies the goal of the interpretation activity (the activity of interpretation is explored further below). Similarly, humans acting as active resources may use knowledge on activity sustainability goals as a passive resource in implementation activities, with the goal of altering activity behaviour so that sustainability goals are fulfilled. Thus, it may be seen that in human efforts towards sustainability, two sets of activities are involved: (i) the activities whose operation we are trying to maintain; and (ii) the activities we undertake in order to manage the behaviour of (i).

To characterise the external and interpreted worlds from a sustainability perspective, we may map the concepts of systems, activities, and knowledge to each world by considering the activity of human interpretation. Firstly, systems may be considered to exist in the external world. However, as highlighed in Section 3.1, systems "are in the eye of the beholder" (Thomé, 1993, p.4). As such, whilst they exist in the external world, systems may be considered to be defined for study in the interpreted world. That is, humans interpret the world around them to produce knowledge on a particular system of interest, as shown in Figure 12. Thus, systems may be considered to exist in the external world, but knowledge on the systems under study may be viewed as existing in the interpreted world, again shown in Figure 12.

Like systems, activities may be considered to operate in the external world. However, as shown in Section 4.1, activities must also be defined for study by humans (O'Donnell and Duffy, 2005), e.g. by applying the formalism provided in Figure 1 in Section 4.1. Therefore, in the same manner as humans define systems, they interpret the world around them to produce knowledge on activities in a particular system of interest. As such, activities may be viewed as existing in the external world, but knowledge on the activities under study exists in the interpreted world, as shown in Figure 12. 
Finally, as shown above, humans interpret the external world to produce knowledge on that world that is held within the the human mind. To provide further examples, humans interpret the behaviour of activities to produce knowledge on their current behaviour and how they should behave with respect to sustainability (i.e. knowledge on sustainability goals), and their behaviour in relation to sustainability goals (shown in Figure 12 above). As such, knowledge may be viewed as existing solely within the interpreted world. However, note that knowledge may be represented in the external world (Newell, 1982). For example, in this paper, knowledge on the operation of activities in the Earth system and its sub-systems from the perspective of sustainability has been represented in the form of the S-Cycle model (Figure 11), that exists in the external world. Furthermore, knowledge existing in the interpreted world may be transformed into effects in the external world via action, as highlighted by Gero and Kannengiesser (2004) above.

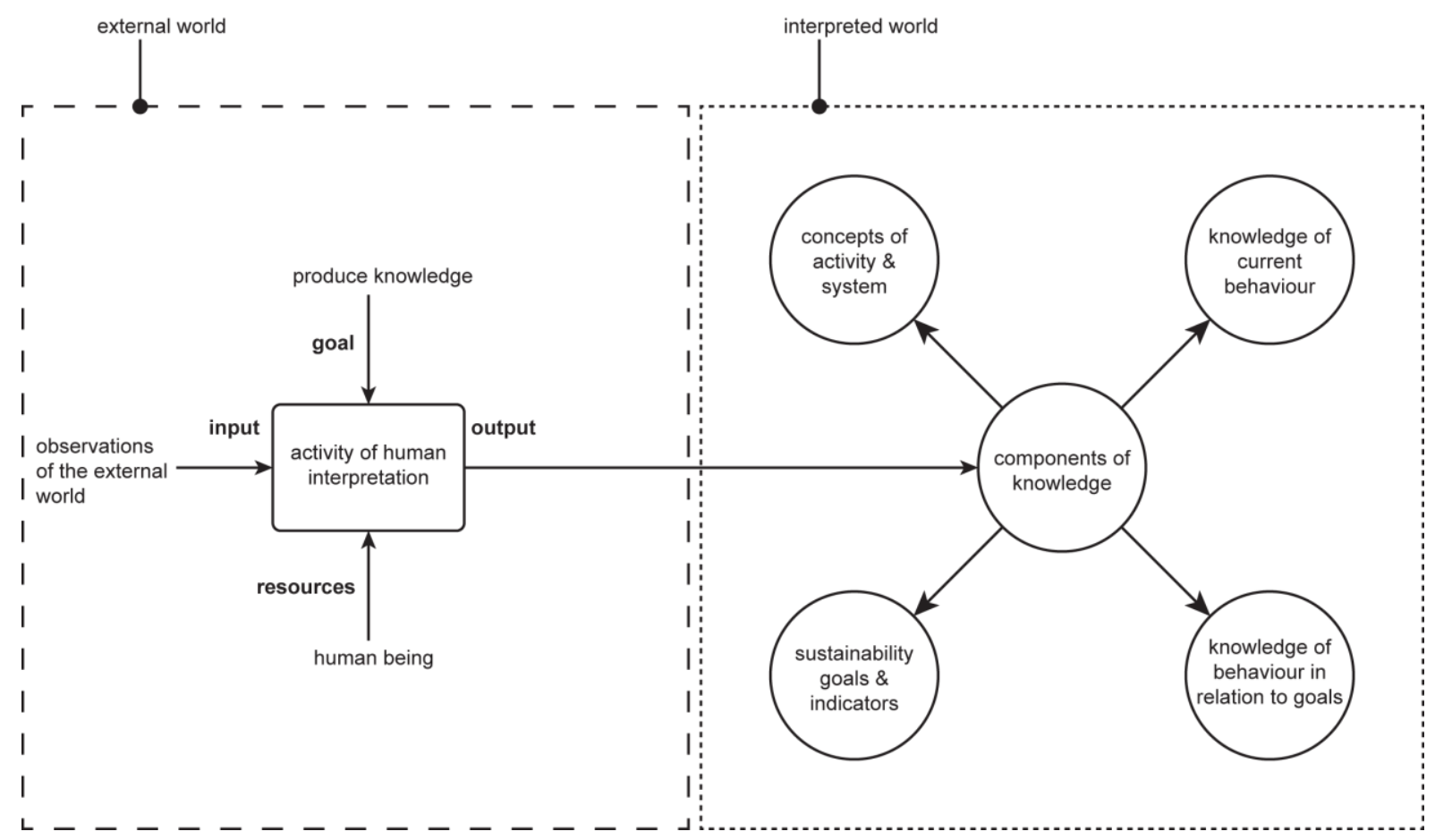

Fig 12. The activity of interpretation, where observations of the external world are used as a passive resource by humans (i.e. active resources), to produce knowledge that exists in the interpreted world.

In the S-Loop model, systems (Figure 10) and activities (Figure 11) are represented in the external world, whilst key components of knowledge employed in human action towards sustainability (Figure 12) are represented in the interpreted world. These three entities, i.e. systems, activities, and knowledge, are linked via the iterative process of interpretation and action outlined previously. The entities are presented at different levels so that they may be positioned relative to one another, according to their roles in the iterative process. The model is presented in Figure 13, and is described in relation to the literature it was induced from below. 


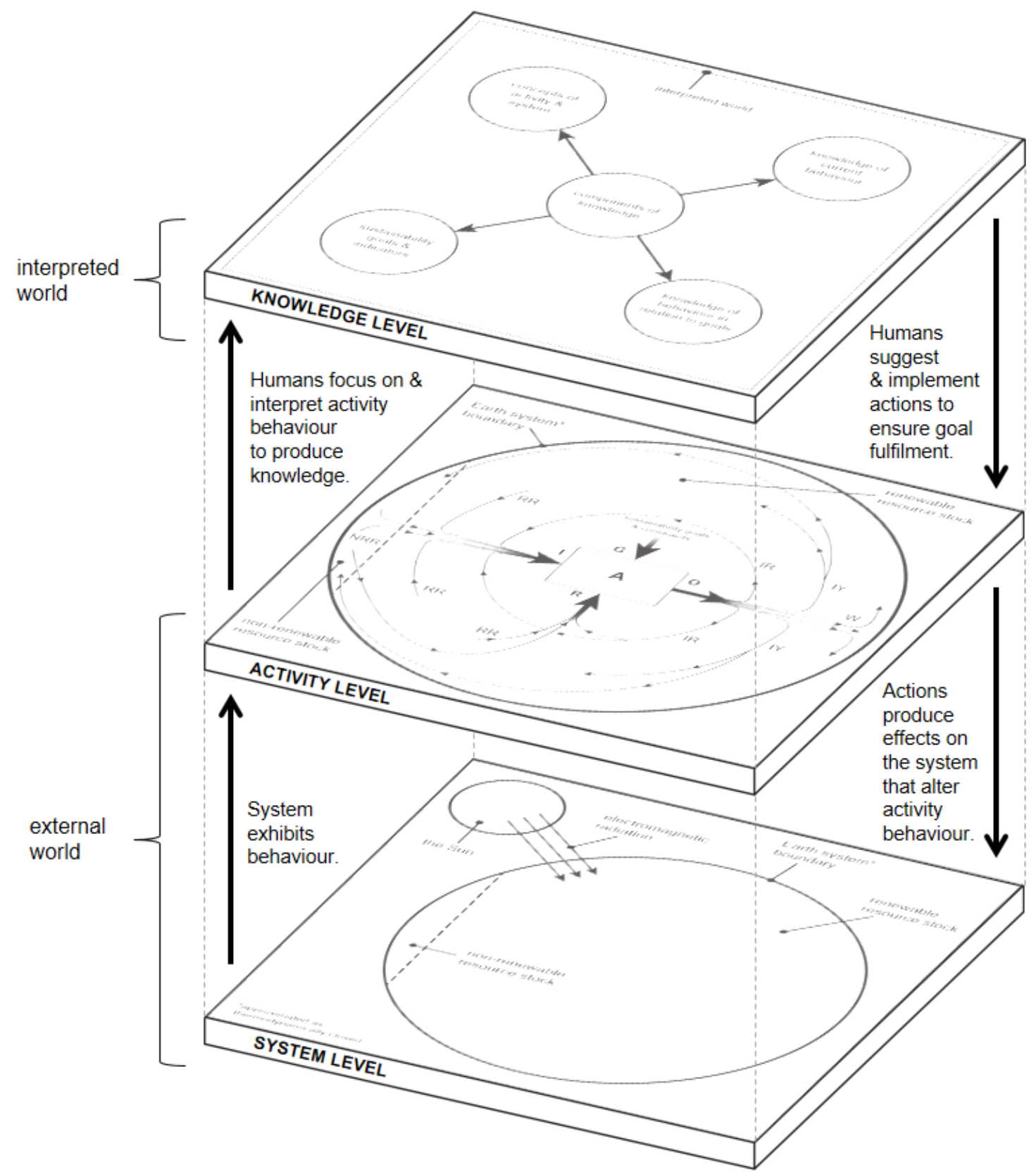

Fig 13. The Sustainability Loop (S-Loop model), describing human efforts towards sustainability as an iterative process of knowledge production and action, involving systems, activities, and knowledge.

As shown in the S-Loop model, the Earth system, like all systems, exhibits behaviour, i.e. it "does something". This behaviour is exhibited by the structure of the system (Gero and Kannengiesser, 2004; Wang et al., 2008), i.e. by its components and relationships (Tully, 1993) (discussed in Section 3.1). In turn, humans may focus on the behaviour of activities operating in the system. The behaviour of an activity may be viewed as the behaviour exhibited by the particular set of system components (i.e. passive and active resources, and outputs) involved in the activity (discussed in Section 4.1). In Section 3.2 , it was shown that humans per se may be viewed as integral components of the Earth system (Beddoe et al., 2009; Dawson et al., 2010). Thus, we may consider humans to 
exist as components of the Earth system at the system level in the S-Loop model. In turn, given that interpretation and action may be viewed as activities as discussed above (Gero and Kannengiesser, 2004), it may be seen that humans carry out interpretation and actions at the activity level in the S-Loop. Humans may be viewed as active resources in these activities.

In the S-Loop model, the iterative process that emerges from the literature covered in Section 5 (outlined above) is described as follows. Humans interpret the behaviour of activities in a particular system of interest (i.e. sub-system of the Earth system) in the external world (Jordan et al., 2010; Walter and Stützel, 2009), to produce knowledge on current behaviour and how the activities should behave with respect to sustainability, i.e. knowledge on sustainability goals (Ness et al., 2007; O'Donnell and Duffy, 2005) (formulated on the basis of (i) the physical laws and limits of the Earth system (Daly, 1990), and (ii) the moral and social standards of humans (Kajikawa, 2008; Walter and Stützel, 2009), as discussed in Section 5.1). Both of these knowledge elements exist at the knowledge level in the interpreted world. On the basis of this knowledge, humans may suggest actions to be taken, that are expected to result in the activities fulfilling their goals. They may then actually take action at the activity level of the external world (Eurostat, 2011a; Parris and Kates, 2003), to produce effects on the system components involved in the activities (existing at the system level of the external world). These effects bring about a change in the behaviour of the activities at the activity level of the external world (discussed in Section 5.1). To determine if activities have fulfilled, or are on track to fulfil their sustainability goals, humans interpret activity behaviour after the goals have been implemented by defining and evaluating SIs (Ness et al. 2007; Jordan et al. 2010; Ramos and Caeiro 2010; Rametsteiner et al. 2011; van Zeijl-Rozema and Martens 2010; Singh et al. 2012). In other words, they carry out sustainbility assessment (Bodini, 2012; Ness et al., 2007) at the activity level of the external world (discussed in Section 5.2). Like knowledge on current behaviour and sustainability goals, knowledge on post-action activity behaviour exists at the knowledge level in the interpreted world. On the basis of the latter component of knowledge, humans may again suggest actions to be taken regarding the sustainability of the activities and/or the system of interest as a whole (given that sustainability may be viewed as an emergent property of a system (Bodini, 2012; Godfrey, 2010; Wahl and Baxter, 2008), as discussed in Section 4.3). For example, if activities are found not to be on track to fulfil their sustainability goals, humans may suggest actions that are expected to result in the goals being fulfilled in future. Alternatively, they may use this knowledge as a basis from which to begin the whole process again in the context of a different system of interest, having learned from experience.

As will be demonstrated in Section 6.3, the S-Loop model may be applied to guide efforts towards sustainability in the context of a particular system of interest. A key activity described in the S-Loop is interpreting the behaviour of activities in a system to 
produce knowledge on current behaviour and sustainability goals. Since it describes the operation of activities in a system from the perspective of sustainability, the S-Cycle model may be used to guide this interpretation activity. Thus, the S-Cycle model may be applied complementary to the S-Loop model, to support the interpretation activities described in the latter.

\subsection{The S-Cycle and S-Loop models in practice}

Research is currently under way to explore the validity of the S-Cycle and S-Loop models in depth, and their applicability and usefulness in practice. Nonetheless, to illustrate their intended use, a brief demonstration is provided in this section by applying the models to a system described in Ulgiati et al. (2011, p.182): a production system for the industrial conversion of corn into bioethanol. The authors provide an energy systems diagram for the system, presented in Figure 14. This diagram, along with its accompanying description, provided the majority of the data required to briefly apply the S-Cycle and S-Loop models; however, certain data were extracted from a table of SIs provided on p.181 of Ulgiati et al. (2011). As we show below, the S-Loop model may be applied to provide guidance on how to shift the system towards sustainability, whilst the S-Cycle model may be applied to support interpretation of the behaviour of activities in the system.

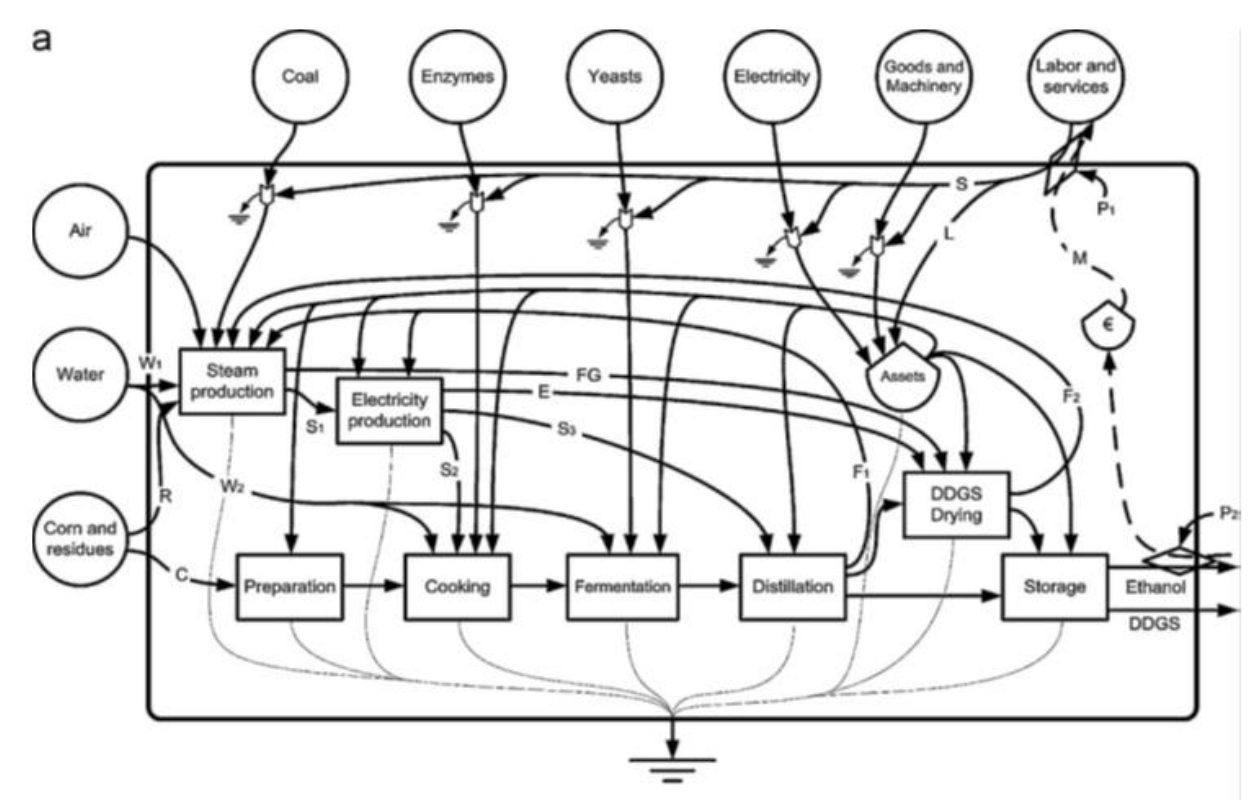

b

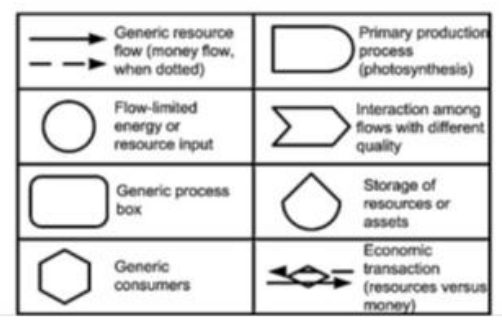


Fig 14. Energy systems diagram of a bioethanol production system (from Ulgiati et al. 2011).

According to the S-Loop model, humans seeking sustainability in a particular system of interest (SOI) must first interpret the behaviour of activities operating in the system. This activity should yield knowledge on current activity behaviour, and activity sustainability goals. To carry out this task, we may apply the S-Cycle model to the production system described in Ulgiati et al. (2011, pp.180-182). Firstly, we will define the boundary of the SOI to include the bioethanol plant, and also the resource stocks providing its direct inputs as described in the energy systems diagram in Figure 14 above. Next, we must define the activities whose behaviour we will focus on within the SOI. As shown in Figure 14, Ulgiati et al. (2011, p.182) describe a number of interconnected "process steps" within the production system. Using the S-Cycle model, each of these process steps may be represented as an activity. For example, in Figure 14 , it may be seen that DDGS drying has the following inputs: electricity, flue gases, goods and machinery, labour and services, and distilled corn. The output of this process step consists of warm gases, and DDGS. Assuming that labour and machinery use electricity, flue gases, goods and services, and distilled corn to produce DDGS, we may represent DDGS drying as an activity as shown in Figure 15. Labour and machinery may be classed as active resources (i.e. resources that use other resources in an activity (Boyle et al., 2009)), whilst electricity, flue gases, goods and services, and distilled corn may be classed as passive resources (i.e. resources used by active resources in an activity (Boyle et al., 2009)). DDGS represents the output of the activity, and "produce DDGS" may be viewed as a high-level goal of the activity.

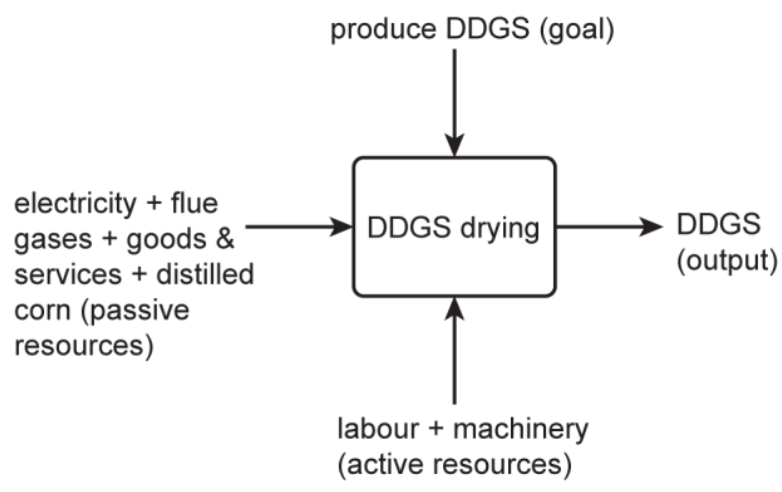

Fig 15. DDGS from Ulgiati et al. (2011) represented as an activity.

Although we may represent each of the process steps as an individual activity using the S-Cycle model, this would make for a rather in-depth treatment of the SOI that would likely exceed the necessary space limitations of a journal article. Therefore, we may instead represent the aggregate of these activities, i.e. the activity of "bioethanol production" as shown in Figure 16. Using the S-Cycle model, we may interpret the behaviour of this activity within the SOI as shown in Figure 16. The activity is carried 
out by labour, machinery, enzymes, and yeasts (renewable active resources), that use air, water, corn and residues, electricity, and goods and services (renewable passive resources), along with coal (non-renewable passive resource), to produce an output consisting of: ethanol and DDGS (intended yield); high pressure steam, low pressure steam, electricity, flue gases, low pressure water condensate, and warm gases (intended resources); and solid emissions and greenhouse gases (waste). Note that the intended resources were identifed as the inputs to process steps that originate from other process steps included in the overall activity of bioethanol production. That is, resources produced by the bioethanol production activity that are intended for use in the activity itself. Note also that the bioethanol production activity does not use any non-renewable active resources, does not produce any yield that may be considered to be non-renewable, and does not produce any intended active resources (only intended passive resources).

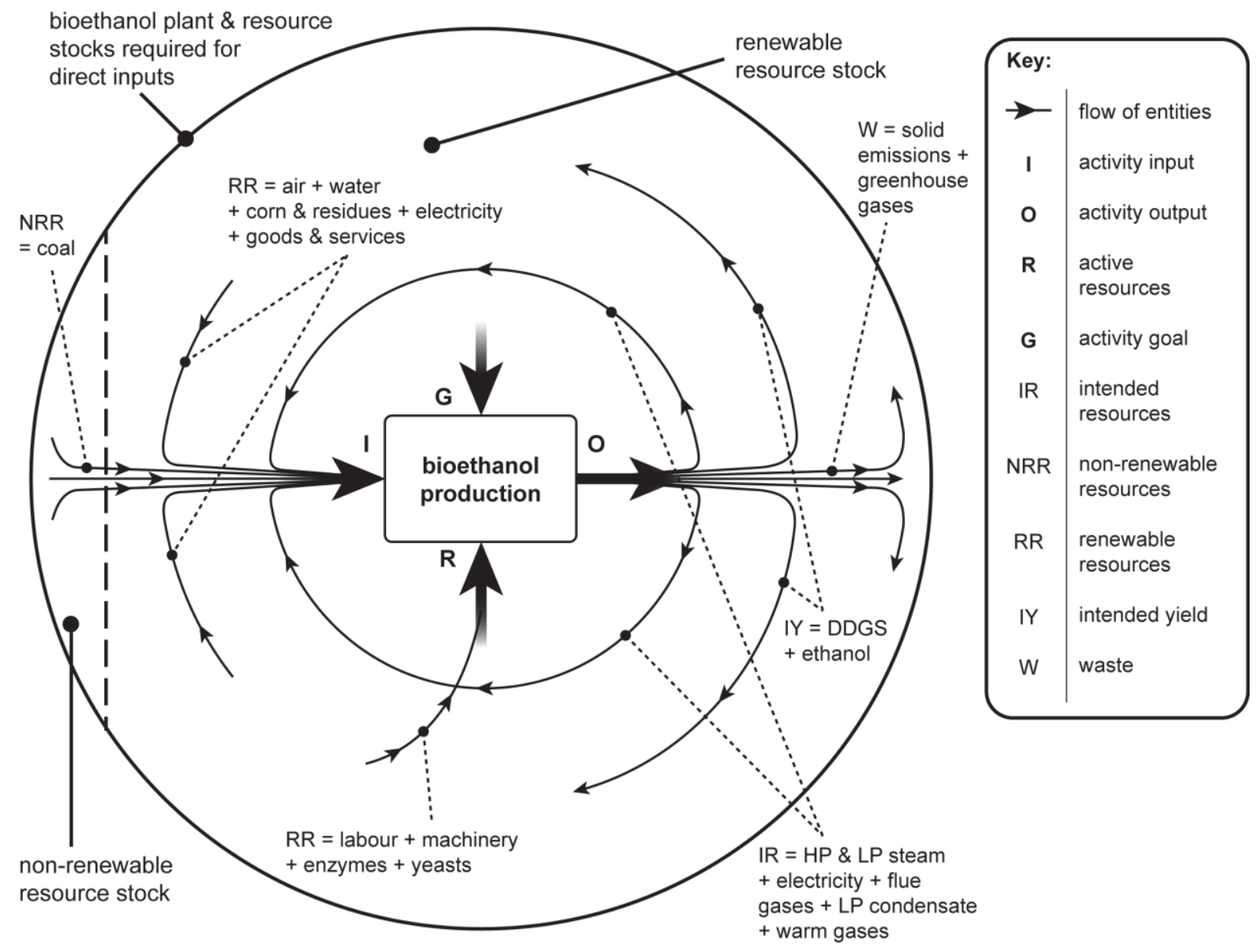

Fig 16. Interpretation of the behaviour of a bioethanol production activity using the S-Cycle model.

We may now interpret the behaviour of the bioethanol production activity, represented in Figure 16, to set sustainability goals for the activity. For example, we may formulate the following goals, among others: 
1. Minimise coal use (since activities should not use non-renewable resources (Daly, 1990), as discussed in Section 5.1).

2. Minimise solid emissions (since activities should not produce excessive waste (Daly, 1990), as discussed in Section 5.1).

3. Minimise greenhouse gas emissions (for the same reason as goal 2 above).

4. Maximise the fraction of the electricity input that comes from the intended resources stream (to improve the activity's ability to continue operating in the event of disruption to the external electricity supply).

5. Ensure that ethanol produced meets the quality standards of humans (since any ethanol that does not meet these standards may have to be disposed of, i.e. represents waste and also, to eliminate any negative social impacts that may arise from the continued production of poor quality ethanol).

Next, the S-Loop model prescribes that we must suggest and then implement actions that are expected to result in the activity fulfilling its sustainability goals. Without access to the actual system, it is rather difficult to suggest realistic actions.

Furthermore, it is not possible to demonstrate the implementation of these actions here. However, for the purposes of this simple analysis, the following actions may be generally expected to result in the fulfillment of the above goals:

- To fulfil goals 1 and 3, we may install a renewable energy production system (e.g. a solar system) within the bioethanol plant to replace or reduce the input of coal.

- To fulfil goal 2, we may set up a scheme whereby the solid emissions from the plant are captured and recycled or stored.

- To fulfil goal 4, we may increase the internal energy production of the activity by installing electricity production equipment with a higher output capacity in the bioethanol plant.

- To fulfil goal 5, we may ensure that equipment in the plant is cleaned regularly, that adequate training is provided for human resources, and that the best quality yeast and enzymes are used in the plant.

Finally, according to the S-Loop model, we must interpret the post-action behaviour of the bioethanol production activity by carrying out sustainability assessment. That is, by defining SIs that allow us to assess the behaviour of the activity in relation to its sustainability goals, and then evaluating these SIs to produce knowledge on that behaviour. Ulgiati et al. (2011, p.181) provide a set of SIs for bioethanol production, along with SI values. Some of these may be used to assess the behaviour of the bioethanol production activity (represented in Figure 16) in relation to the sustainability goals defined above. In other cases, example SIs have been defined below. Again, without access to the actual system, it is not possible to evaluate these SIs to produce knowledge on activity behaviour, and there is no guarantee that these SIs would be measurable in practice. They are intended as examples only. 
- To assess activity behaviour in relation to goal 1 , we may, for instance, define the SI 'tons of coal consumed per unit of bioethanol produced.'

- To assess behaviour in relation to goal 2, we may define the SI 'grams of solid emissions per unit of bioethanol produced' (Ulgiati et al., 2011).

- To assess behaviour in relation to goal 3, we may define the SI 'grams of CO2 equivalent produced per gram of bioethanol produced' (Ulgiati et al., 2011).

- To assess behaviour in relation to goal 4, we may define the SI 'internally produced electricity consumed as a fraction of the total electricity input per annum.'

- To assess behaviour in relation to goal 5, we may define the SI 'number of satisfied customers per 1000 customers.' Alternatively, we may define a qualitative, subjective indicator such as 'perceived quality of ethanol by customers.'

If we were to evaluate the SIs suggested above, we may be able to determine whether or not the bioethanol production activity is on track to fulfil its sustainability goals or not, and suggest an appropriate course of action in this respect. For example, if we evaluated the SI 'grams of solid emissions per unit of bioethanol produced' over a period of several months and found that the value of the SI was continually rising, this may indicate that the activity is not on track to fulfil goal 2 above. In turn, we may suggest and take action to, for instance, accelerate the implementation of a scheme to capture and recycle or store solid emissions (outlined above).

\section{Conclusion}

In spite of a considerable body of research on sustainability, recent reports suggest that we are barely any closer to a more sustainable society (Eurostat, 2011; UNEP, 2012). There is an urgent need to improve the effectiveness of human efforts towards sustainability. A clearer and more unified understanding of sustainability among different people and sectors could help to facilitate this (Hannon and Callaghan, 2011; Lindsey, 2011). Along these lines, this paper has presented the results of an inductive literature investigation focusing on sustainability and human action towards it across society. The aim was to develop models to explain the nature of sustainability in the Earth system, and how humans in different sectors may effectively strive for it. The major contributions made by the investigation are two general and complementary models, developed via a process of induction from the literature: (i) the Sustainability Cycle (S-Cycle), describing the operation of activities in a system from the perspective of sustainability; and (ii) the Sustainability Loop (S-Loop), describing a basic process that may lead humans towards sustainability in the context of a particular system of interest. 
Literature from multiple sectors identified as major contributors to sustainability research was selected for review, to gain a view that is as free from contextual nuances as possible. From this literature, three concepts emerged as significant for detailed investigation in relation to our aim: (i) systems, as the context for human action towards sustainability (Bell and Morse, 2008; Bodini, 2012; Fiksel, 2003); (ii) activities, as a fundamental target that humans need to sustain within the Earth system (given their instrumental role in producing the entities both needed and desired by society (O'Donnell and Duffy, 2005)); and (iii) knowledge, as the driver of human action towards sustainability (Meadows, 1998; Newell, 1982). In Section 3, the Earth system was characterised as the ultimate context for human action towards sustainability (UNEP, 2012), and different sub-systems of this overall system were discussed. In Section 4, the concept of an activity was introduced, and the basic behaviour of activities operating in the Earth system was outlined. It was shown that sustainability may be viewed either as a property of an individual activity in a system, or an emergent property of a particular system of interest (Bodini, 2012; Godfrey, 2010; Wahl and Baxter, 2008). Humans may influence the behaviour of activities in a system towards what is required for sustainability by implementing activity sustainability goals (Eurostat, 2011; Parris and Kates, 2003; Quental et al., 2011). Finally, in Section 5, it was shown that humans formulate sustainability goals by interpreting the behaviour of activities in a particular system of interest. The formulation of these goals is goverened by (i) the physical laws and limits of the Earth system (Daly, 1990), and (ii) the moral and social standards of humans (Kajikawa, 2008; Walter and Stützel, 2009). The goals are implemented via actions (Eurostat, 2011a; Parris and Kates, 2003) that produce effects on the system components involved in the activities, resulting in a change in activity behaviour. To determine if the goals are being fulfilled or not, humans interpret activity behaviour after they have been implemented by defining and evaluating SIs (Ness et al. 2007; Jordan et al. 2010; Ramos and Caeiro 2010; Rametsteiner et al. 2011; van Zeijl-Rozema and Martens 2010; Singh et al. 2012).

In Sections 6.1 and 6.2, the S-Cycle and S-Loop models were introduced and discussed in relation to the literature that they were induced from. The S-Cycle model describes the Earth system and its sub-systems as being comprised of renewable and non-renewable resource stocks, that are consumed and replenished by both natural and human activities. These activities transform input flows of renewable and non-renewable passive and active resources into output flows of: (i) intended resources, i.e. entities intended for use in the activity itself (Costanza and Daly 1992; Ekins 2011); (ii) intended yield, i.e. entities to be yielded to the wider system (Brown and Ulgiati 1997; Campbell and Garmestani 2012; Ekins 2011; Liao et al. 2011), either to be used in other activities or to contribute to resource stocks in the system; and (iii) waste, i.e. entities with no utility to the activity (Barles 2010; Brown and Ulgiati 1997; Marchettini et al. 2007; Rosen et al. 2008; Zhang et al. 2011), that may be used in other activities or contribute to waste accumulations in the system. The ability of activities in the system 
to continue to operate (i.e. their sustainability) fundamentally depends upon the availability of resources in the system. In turn, the availability of resources in the system fundamentally depends upon the rate at which they are consumed and replenished by activities. Humans may intervene in these dynamics by implementing sustainability goals and indicators for activities, as described in the S-Loop model below.

The S-Loop model describes human efforts towards sustainability as an iterative process of interpretation and action involving the aforementioned three concepts. In the S-Loop, humans interpret the behaviour of activities in a system to produce knowledge on: (i) their current behaviour (Meadows, 1998); and (ii) how the activities should behave for sustainability (Derissen et al., 2011), i.e. sustainability goal knowledge (O’Donnell and Duffy, 2005). This knowledge serves as a basis for suggesting and implementing actions that are expected to result in the activities fulfilling their sustainability goals. Humans then interpret the behaviour of activities after actions have been taken, by evaluating sustainability indicators to produce knowledge on resulting activity behaviour in relation to sustainability goals (Jordan et al., 2010; Ness et al., 2007; van Zeijl-Rozema and Martens, 2010). This knowledge may then be used as a basis for suggesting and implementing further actions. For instance, if activities are found not to be on track to fulfil their sustainability goals, humans may suggest actions that are expected to result in the goals being fulfilled in future. Alternatively, they may use this knowledge as a basis from which to begin the whole process again in the context of a different system of interest, having learned from experience.

In Section 6.3, a brief demonstration of the models was provided by applying them to a bioethanol production system described in the literature (Ulgiati et al., 2011). It was shown that the S-Loop model may be used to guide efforts towards sustainability in the context of a particular system of interest, by prescribing the basic activities that should be undertaken. A key activity described in the S-Loop model is interpreting the behaviour of activities in a particular system of interest, to produce knowledge on current behaviour and sustainability goals. The S-Cycle model can support this activity, by highlighting the aspects of activity behaviour that fundamentally affect sustainability in a system. Thus, as shown in Section 6.3, the S-Cycle model may be applied complementary to the S-Loop model, to support the interpretation activities described in the latter. More fundamentally, the S-Cycle can explain the nature of sustainability in the Earth system in general terms (i.e. in terms of systems and activities), and thus, provides a common language for discussing sustainability both within and across different sectors. Given their general nature, the models provide the basis for a more unified understanding of sustainability among different people and sectors. Further research is under way to explore the validity and applications of the models. However, it is hoped that their use may go some way towards improving the effectiveness of human action towards sustainability. 


\section{Acknowledgements}

The authors gratefully acknowledge the University of Strathclyde for funding the research documented in this paper through the award of a University of Strathclyde Research Studentship.

\section{References}

Alfaris, A., Siddiqi, A., Rizk, C., de Weck, O., Svetinovic, D., 2010. Hierarchical Decomposition and Multidomain Formulation for the Design of Complex Sustainable Systems. J. Mech. Des. 132, 091003-1 - 091003-13.

Alfsen, K.H., Greaker, M., 2007. From natural resources and environmental accounting to construction of indicators for sustainable development. Ecol. Econ. 61, 600-610.

Barles, S., 2010. Society, energy and materials: the contribution of urban metabolism studies to sustainable urban development issues. J. Environ. Plan. Manag. 53, 439-455.

Baumgärtner, S., Quaas, M., 2010. What is sustainability economics? Ecol. Econ. 69, 445450.

Beddoe, R., Costanza, R., Farley, J., Garza, E., Kent, J., Kubiszewski, I., Martinez, L., McCowen, T., Murphy, K., Myers, N., Ogden, Z., Stapleton, K., Woodward, J., 2009. Overcoming systemic roadblocks to sustainability: the evolutionary redesign of worldviews, institutions, and technologies. Proc. Natl. Acad. Sci. U. S. A. 106, 2483-2489.

Bell, S., Morse, S., 2008. Sustainability indicators: measuring the immeasurable?, 2nd ed. Earthscan, London.

Benoît, C., Mazjin, B., Andrews, E.S., Barthel, L.-P., Ciroth, A., Cucuzzella, C., Gensch, C.O., 2009. Guidelines for Social Life Cycle Assessment of Products. United Nations Environment Programme, Druk in de weer, Belgium.

Blanchard, B.S., Fabrycky, W.J., 1981. Systems Engineering and Analysis. Prentice-Hall, Inc., Englewood Cliffs, New Jersey.

Bodini, A., 2012. Building a systemic environmental monitoring and indicators for sustainability: What has the ecological network approach to offer? Ecol. Indic. 15, 140148.

Boyle, I.M., Duffy, A.H.B., Whitfield, R.I., Liu, S., 2009. Towards an understanding of the impact of resources on the design process, in: 17th International Conference on Engineering Design (ICED `09). The Design Society, Stanford.

Boyle, I.M., Duffy, A.H.B., Whitfield, R.I., Liu, S., 2012. The impact of resources on decision making. Artif. Intell. Eng. Des. Anal. Manuf. 26, 407-423. 
Brown, B.J., Hanson, M.E., Liverman, D.M., Merideth, R.W., 1987. Global sustainability: Toward definition. Environ. Manage. 11, 713-719.

Brown, M.., Ulgiati, S., 1997. Emergy-based indices and ratios to evaluate sustainability: monitoring economies and technology toward environmentally sound innovation. Ecol. Eng. 9, 51-69.

Brown, M.T., Odum, H.T., Jorgensen, S.., 2004. Energy hierarchy and transformity in the universe. Ecol. Modell. 178, 17-28.

Burger, P., Christen, M., 2011. Towards a capability approach of sustainability. J. Clean. Prod. 19, 787-795.

Cabezas, H., Pawlowski, C.W., Mayer, A.L., Hoagland, N.T., 2005. Sustainable systems theory: ecological and other aspects. J. Clean. Prod. 13, 455-467.

Campbell, D.E., Garmestani, A.S., 2012. An energy systems view of sustainability: emergy evaluation of the San Luis Basin, Colorado. J. Environ. Manage. 95, 72-97.

Celino, A., Concilio, G., 2010. Explorative Nature of Negotiation in Participatory Decision Making for Sustainability. Gr. Decis. Negot. 20, 255-270.

Çengel, Y.A., Turner, R.H., 2004. Fundamentals of thermal-fluid sciences, 2nd ed. McGraw-Hill, Boston, London.

Chapman, J., 2011. Emotionally Durable Design, 3rd ed. Earthscan, London, Washington DC.

Conway, G.R., 1986. Agroecosystem analysis for research and development. Winrock International, Bangkok.

Coppola, F., Bastianoni, S., Østergård, H., 2009. Sustainability of bioethanol production from wheat with recycled residues as evaluated by Emergy assessment. Biomass and Bioenergy 33, 1626-1642.

Costanza, R., Daly, H.E., 1992. Natural Capital and Sustainable Development. Conserv. Biol. 6, 37-46.

Costanza, R., Patten, B.C., 1995. Defining and predicting sustainability. Ecol. Econ. 15, 193-196.

Daly, H.E., 1990. Toward some operational principles of sustainable development. Ecol. Econ. 2, 1-6.

Daly, H.E., 1992. Steady-state economics, 2nd ed. Earthscan, London.

Darnhofer, I., Fairweather, J., Moller, H., 2010. Assessing a farm's sustainability: insights from resilience thinking. Int. J. Agric. Sustain. 8, 186-198. 
Dawson, T.P., Rounsevell, M.D.A., Kluvánková-Oravská, T., Chobotová, V., Stirling, A., 2010. Dynamic properties of complex adaptive ecosystems: implications for the sustainability of service provision. Biodivers. Conserv. 19, 2843-2853.

De Lara, M., Martinet, V., 2009. Multi-criteria dynamic decision under uncertainty: a stochastic viability analysis and an application to sustainable fishery management. Math. Biosci. 217, 118-24.

De Smedt, P., 2010. The Use of Impact Assessment Tools to Support Sustainable Policy Objectives in Europe. Ecol. Soc. 15.

Dempsey, N., Bramley, G., Power, S., Brown, C., 2011. The social dimension of sustainable development: Defining urban social sustainability. Sustain. Dev. 19, 289-300.

Derissen, S., Quaas, M.F., Baumgärtner, S., 2011. The relationship between resilience and sustainability of ecological-economic systems. Ecol. Econ. 70, 1121-1128.

Duffy, A., 2005. Design process and performance, in: Clarkson, J., Huhtala, M. (Eds.), Engineering Design - Theory and Practice, A Symposium in Honour of Ken Wallace. Engineering Design Centre, University Of Cambridge, pp. 76-85.

Dyllick, T., Hockerts, K., 2002. Beyond the business case for corporate sustainability. Bus. Strateg. Environ. 11, 130-141.

Ehrlich, P.R., Ehrlich, A.H., 2013. Can a collapse of global civilization be avoided? Proc. Biol. Sci. 280, 20122845.

Ekins, P., 2011. Environmental sustainability: From environmental valuation to the sustainability gap. Prog. Phys. Geogr. 35, 629-651.

Ekins, P., Simon, S., Deutsch, L., Folke, C., De Groot, R., 2003. A framework for the practical application of the concepts of critical natural capital and strong sustainability. Ecol. Econ. 44, 165-185.

Ertesvag, I.S., 2005. Energy, exergy, and extended-exergy analysis of the Norwegian society 2000. Energy 30, 649-675.

European Commission, 2009. Commission Impact Assessment Guidelines [WWW Document]. URL

http://ec.europa.eu/governance/impact/commission_guidelines/commission_guidelin es_en.htm

Eurostat, 2010. Eurostat Quality Profile - Gross Domestic Product (GDP) per capita in Purchasing Power Standards (PPS) [WWW Document]. Eurostat Qual. Profile - Gross Domest. Prod. per capita Purch. Power Stand. URL

http://epp.eurostat.ec.europa.eu/portal/page/portal/sdi/files/QP GDP per capita in PPS.pdf 
Eurostat, 2011a. Sustainable development in the European Union - 2011 monitoring report of the EU sustainable development strategy. Publications Office of the European Union, Luxembourg.

Eurostat, 2011b. Material flow accounts - Statistics Explained [WWW Document]. URL http://epp.eurostat.ec.europa.eu/statistics_explained/index.php/Material_flow_account $\mathrm{s}$

Figge, F., Hahn, T., 2005. The Cost of Sustainability Capital and the Creation of Sustainable Value by Companies. J. Ind. Ecol. 9, 47-58.

Fiksel, J., 2003. Designing Resilient, Sustainable Systems. Environ. Sci. Technol. 37, 5330-5339.

Gagnon, B., Leduc, R., Savard, L., 2012. From a conventional to a sustainable engineering design process: different shades of sustainability. J. Eng. Des. 23, 49-74.

Gaichas, S.K., 2008. A context for ecosystem-based fishery management: Developing concepts of ecosystems and sustainability. Mar. Policy 32, 393-401.

Galli, A., Kitzes, J., Niccolucci, V., Wackernagel, M., Wada, Y., Marchettini, N., 2012. Assessing the global environmental consequences of economic growth through the Ecological Footprint: A focus on China and India. Ecol. Indic. 17, 99-107.

Garmendia, E., Stagl, S., 2010. Public participation for sustainability and social learning: Concepts and lessons from three case studies in Europe. Ecol. Econ. 69, 1712-1722.

Gasparatos, A., El-Haram, M., Horner, M., 2009a. Assessing the sustainability of the UK society using thermodynamic concepts: Part 1. Renew. Sustain. Energy Rev. 13, 10741081.

Gasparatos, A., El-Haram, M., Horner, M., 2009b. Assessing the sustainability of the UK society using thermodynamic concepts: Part 2. Renew. Sustain. Energy Rev. 13, 956970.

Gatto, M., 1995. Sustainability: Is it a well defined concept? Ecol. Appl. 5, 1181-1183.

Gero, J.S., Kannengiesser, U., 2004. The situated function-behaviour-structure framework. Des. Stud. 25, 373-391.

Godfrey, P., 2010. Using systems thinking to learn to deliver sustainable built environments. Civ. Eng. Environ. Syst. 27, 219-230.

Goerner, S.J., Lietaer, B., Ulanowicz, R.E., 2009. Quantifying economic sustainability: Implications for free-enterprise theory, policy and practice. Ecol. Econ. 69, 76-81.

Hahn, T., Figge, F., 2011. Beyond the Bounded Instrumentality in Current Corporate Sustainability Research: Toward an Inclusive Notion of Profitability. J. Bus. Ethics 104, 325-345. 
Hahn, W.A., Knoke, T., 2010. Sustainable development and sustainable forestry: analogies, differences, and the role of flexibility. Eur. J. For. Res. 129, 787-801.

Hak, T., Kovanda, J., Weinzettel, J., 2012. A method to assess the relevance of sustainability indicators: Application to the indicator set of the Czech Republic's Sustainable Development Strategy. Ecol. Indic. 17, 46-57.

Hannon, A., Callaghan, E.G., 2011. Definitions and organizational practice of sustainability in the for-profit sector of Nova Scotia. J. Clean. Prod. 19, 877-884.

Hansen, J.W., 1996. Is agricultural sustainability a useful concept? Agric. Syst. 50, 117143.

Hart, S.L., Milstein, M.B., 2003. Creating sustainable value. Acad. Manag. Exec. 17, 56-69.

Heal, G., 2012. Reflections - Defining and Measuring Sustainability. Rev. Environ. Econ. Policy 6, 147-163.

Heijungs, R., Huppes, G., Guinée, J.B., 2010. Life cycle assessment and sustainability analysis of products, materials and technologies. Toward a scientific framework for sustainability life cycle analysis. Polym. Degrad. Stab. 95, 422-428.

Holling, C.S., 2001. Understanding the Complexity of Economic, Ecological, and Social Systems. Ecosystems 4, 390-405.

Hubka, V., Eder, W.E., 1988. Theory of Technical Systems, 2nd ed. Springer-Verlag, Berlin, Heidelberg, New York.

Jamieson, D., 1998. Sustainability and beyond. Ecol. Econ. 24, 183-192.

Jordan, S.J., Hayes, S.E., Yoskowitz, D., Smith, L.M., Summers, J.K., Russell, M., Benson, W.H., 2010. Accounting for natural resources and environmental sustainability: linking ecosystem services to human well-being. Environ. Sci. Technol. 44, 1530-6.

Kajikawa, Y., 2008. Research core and framework of sustainability science. Sustain. Sci. 3, 215-239.

Kajikawa, Y., Ohno, J., Takeda, Y., Matsushima, K., Komiyama, H., 2007. Creating an academic landscape of sustainability science: an analysis of the citation network. Sustain. Sci. 2, 221-231.

Kim, J., Oki, T., 2011. Visioneering: an essential framework in sustainability science. Sustain. Sci. 6, 247-251.

Kirsch, S., 2009. Sustainable Mining. Dialect. Anthropol. 34, 87-93.

Köhn, J., 1998. Thinking in terms of system hierarchies and velocities. What makes development sustainable? Ecol. Econ. 26, 173-187. 
Komiyama, H., Takeuchi, K., 2006. Sustainability science: building a new discipline. Sustain. Sci. 1, 1-6.

Larkin, P.A., 1977. An Epitaph for the Concept of Maximum Sustained Yield. Trans. Am. Fish. Soc. 106, 1-11.

Lele, S., Norgaard, R.B., 1996. Sustainability and the Scientist's Burden. Conserv. Biol. 10, 354-365.

Li, Y., Yang, Z.F., 2011. Quantifying the sustainability of water use systems: Calculating the balance between network efficiency and resilience. Ecol. Modell. 222, 1771-1780.

Liao, W., Heijungs, R., Huppes, G., 2011. Is bioethanol a sustainable energy source? An energy-, exergy-, and emergy-based thermodynamic system analysis. Renew. Energy 36, 3487-3479.

Lindsey, T.C., 2011. Sustainable principles: common values for achieving sustainability. J. Clean. Prod. 19, 561-565.

Liu, J., Lin, B.-L., Sagisaka, M., 2012. Sustainability assessment of bioethanol and petroleum fuel production in Japan based on emergy analysis. Energy Policy 44, 23-33.

Liu, S., Costanza, R., Farber, S., Troy, A., 2010. Valuing ecosystem services: theory, practice, and the need for a transdisciplinary synthesis. Ann. N. Y. Acad. Sci. 1185, 5478.

Lo, S.-F., 2010. Performance evaluation for sustainable business: a profitability and marketability framework. Corp. Soc. Responsib. Environ. Manag. 17, 311-319.

Maclaren, V.W., 1996. Urban Sustainability Reporting. J. Am. Plan. Assoc. 62, 184-202.

Marchettini, N., Ridolfi, R., Rustici, M., 2007. An environmental analysis for comparing waste management options and strategies. Waste Manag. 27, 562-71.

Marcuse, P., 1998. Sustainability is not enough. Environ. Urban. 10, 103-112.

McCool, S.F., Stankey, G.H., 2004. Indicators of sustainability: challenges and opportunities at the interface of science and policy. Environ. Manage. 33, 294-305.

Meadows, D., 1998. Indicators and information systems for sustainable development. Hartland.

Meadows, D.H., 2008. Thinking in Systems - A Primer. London.

Metcalf, S.S., Widener, M.J., 2011. Growing Buffalo's capacity for local food: A systems framework for sustainable agriculture. Appl. Geogr. 31, 1242-1251.

Ness, B., Urbel-Piirsalu, E., Anderberg, S., Olsson, L., 2007. Categorising tools for sustainability assessment. Ecol. Econ. 60, 498-508. 
Neumayer, E., 2003. Weak versus strong sustainability : exploring the limits of two opposing paradigms, 2nd ed. Edward Elgar, Cheltenham, UK; Northampton, MA.

Newell, A., 1982. The knowledge level. Artif. Intell. 18, 87-127.

Norgaard, R.B., 2010. Ecosystem services: From eye-opening metaphor to complexity blinder. Ecol. Econ. 69, 1219-1227.

Norse, E.A., Brooke, S., Cheung, W.W.L., Clark, M.R., Ekeland, I., Froese, R., Gjerde, K.M., Haedrich, R.L., Heppell, S.S., Morato, T., Morgan, L.E., Pauly, D., Sumaila, R., Watson, R., 2012. Sustainability of deep-sea fisheries. Mar. Policy 36, 307-320.

Noss, R.F., 1993. Sustainable Forestry or Sustainable Forests?, in: Aplet, G.H., Johnson, N., Olson, J.T., Sample, V.A. (Eds.), Defining Sustainable Forestry. Island Press, Washington D.C., pp. 17-43.

O’Donnell, F.J., Duffy, A.H.B., 2005. Design Performance. Springer-Verlag, London.

Odum, H.T., 1994. The emergy of natural capital, in: Jansson, A., Hammer, M., Folke, C., Costanza, R. (Eds.), Investing in Natural Capital - The Ecological Economics Approach to Sustainability. Island Press, Washington D.C., pp. 200-214.

Oxford English Dictionary, 2013. Oxford English Dictionary [WWW Document]. URL http://www.oed.com/

Parris, T.M., Kates, R.W., 2003. Characterizing a sustainability transition: goals, targets, trends, and driving forces. Proc. Natl. Acad. Sci. U. S. A. 100, 8068-73.

Pearce, D., Putz, F.E., Vanclay, J.K., 2003. Sustainable forestry in the tropics: panacea or folly? For. Ecol. Manage. 172, 229-247.

Posner, S.M., Costanza, R., 2011. A summary of ISEW and GPI studies at multiple scales and new estimates for Baltimore City, Baltimore County, and the State of Maryland. Ecol. Econ. 70, 1972-1980.

Pretty, J., 2008. Agricultural sustainability: concepts, principles and evidence. Philos. Trans. R. Soc. Lond. B. Biol. Sci. 363, 447-65.

Pülzl, H., Prokofieva, I., Berg, S., Rametsteiner, E., Aggestam, F., Wolfslehner, B., 2011. Indicator development in sustainability impact assessment: balancing theory and practice. Eur. J. For. Res. 131, 35-46.

Quental, N., Lourenço, J.M., da Silva, F.N., 2010. Sustainability: characteristics and scientific roots. Environ. Dev. Sustain. 13, 257-276.

Quental, N., Lourenço, J.M., da Silva, F.N., 2011. Sustainable Development Policy: Goals, Targets and Political Cycles. Sustain. Dev. 19, 15-29. 
Rainey, D.L., 2006. Sustainable business development : inventing the future through strategy, innovation, and leadership. Cambridge University Press, Cambridge; New York.

Rametsteiner, E., Pülzl, H., Alkan-Olsson, J., Frederiksen, P., 2011. Sustainability indicator development-Science or political negotiation? Ecol. Indic. 11, 61-70.

Ramos, T.B., Caeiro, S., 2010. Meta-performance evaluation of sustainability indicators. Ecol. Indic. 10, 157-166.

Raut, S.P., Ralegaonkar, R.V., Mandavgane, S.A., 2011. Development of sustainable construction material using industrial and agricultural solid waste: A review of wastecreate bricks. Constr. Build. Mater. 25, 4037-4042.

Reber, M., 2011. A theory of value in design.

Robinson, J., Burch, S., Talwar, S., O’Shea, M., Walsh, M., 2011. Envisioning sustainability: Recent progress in the use of participatory backcasting approaches for sustainability research. Technol. Forecast. Soc. Change 78, 756-768.

Rockström, J., Steffen, W., Noone, K., Persson, A., Chapin, F.S., Lambin, E.F., Lenton, T.M., Scheffer, M., Folke, C., Schellnhuber, H.J., Nykvist, B., de Wit, C.A., Hughes, T., van der Leeuw, S., Rodhe, H., Sörlin, S., Snyder, P.K., Costanza, R., Svedin, U., Falkenmark, M., Karlberg, L., Corell, R.W., Fabry, V.J., Hansen, J., Walker, B., Liverman, D., Richardson, K., Crutzen, P., Foley, J.A., 2009. A safe operating space for humanity. Nature 461, 472-5.

Rosen, M.A., Dincer, I., Kanoglu, M., 2008. Role of exergy in increasing efficiency and sustainability and reducing environmental impact. Energy Policy 36, 128-137.

Shearman, R., 1990. The Meaning and Ethics of Sustainability. Environ. Manage. 14, 1-8.

Sim, S.K., 2000. Modelling Learning in Design.

Singh, R.K., Murty, H.R., Gupta, S.K., Dikshit, A.K., 2012. An overview of sustainability assessment methodologies. Ecol. Indic. 15, 281-299.

Skyttner, L., 1996. General Systems Theory - An Introduction. Macmillan Press Ltd, Basingstoke; London.

Sneddon, C., Howarth, R., Norgaard, R., 2006. Sustainable development in a postBrundtland world. Ecol. Econ. 57, 253-268.

Solow, R., 1993. An almost practical step toward sustainability. Resour. Policy 19, 162172.

Spangenberg, J.H., 2011. Sustainability science: a review, an analysis and some empirical lessons. Environ. Conserv. 38, 275-287.

Standal, D., Utne, I.B., 2011. The hard choices of sustainability. Mar. Policy 35, 519-527. 
Stremke, S., van den Dobbelsteen, A., Koh, J., 2011. Exergy landscapes: exploration of second-law thinking towards sustainable landscape design. Int. J. Exergy 8, 148-174.

Thomé, B., 1993. Definition and Scope of Systems Engineering, in: Thomé, B. (Ed.), Systems Engineering: Principles and Practice of Computer-Based Systems Engineering. John Wiley \& Sons Ltd., Chichester, pp. 1-23.

Tilman, D., Cassman, K.G., Matson, P.A., Naylor, R., Polasky, S., 2002. Agricultural sustainability and intensive production practices. Nature 418, 671-7.

Tully, C., 1993. System Development Activity, in: Thomé, B. (Ed.), Systems Engineering: Principles and Practice of Computer-Based Systems Engineering. John Wiley \& Sons Ltd., Chichester, pp. 45-80.

Turner, B.L., 2010. Vulnerability and resilience: Coalescing or paralleling approaches for sustainability science? Glob. Environ. Chang. 20, 570-576.

Ulanowicz, R., Goerner, S., Lietaer, B., Gomez, R., 2009. Quantifying sustainability: Resilience, efficiency and the return of information theory. Ecol. Complex. 6, 27-36.

Ulanowicz, R.E., 1980. An Hypothesis on the Development of Natural Communities. J. Theor. Biol. 85, 223-245.

Ulgiati, S., Ascione, M., Bargigli, S., Cherubini, F., Franzese, P.P., Raugei, M., Viglia, S., Zucaro, A., 2011. Material, energy and environmental performance of technological and social systems under a Life Cycle Assessment perspective. Ecol. Modell. 222, 176-189.

United Nations, 2007. Indicators of Sustainable Development: Guidelines and Methodologies. United Nations, New York.

United Nations Development Programme, 2011. Human Development Report 2011. Palgrave Macmillan, Basingstoke.

United Nations Environment Programme, 2012. GE05 - Environment for the future we want. United Nations Environment Programme, Valletta, Malta.

United States Department of Agriculture Forest Service, 2010. National Report on Sustainable Forests - 2010. Unknown.

Upham, P., Riesch, H., Tomei, J., Thornley, P., 2011. The sustainability of forestry biomass supply for EU bioenergy: A post-normal approach to environmental risk and uncertainty. Environ. Sci. Policy 14, 510-518.

Van Zeijl-Rozema, A., Martens, P., 2010. An adaptive indicator framework for monitoring regional sustainable development - a case study of the INSURE project in Limburg, The Netherlands. Sustain. Sci. Pract. Policy 6, 6-17.

Voinov, A., 2007. Understanding and communicating sustainability: global versus regional perspectives. Environ. Dev. Sustain. 10, 487-501. 
Vos, R.O., 2007. Defining sustainability: a conceptual orientation. J. Chem. Technol. Biotechnol. 82, 334-339.

Vucetich, J.A., Nelson, M.P., 2010. Sustainability: Virtuous or Vulgar? Bioscience 60, 539544.

Wackernagel, M., Rees, W.E., 1997. Perceptual and structural barriers to investing in natural capital: Economics from an ecological footprint perspective. Ecol. Econ. 20, 324.

Wackernagel, M., Yount, D.J., 1998. The Ecological Footprint: an Indicator of Progress Toward Regional Sustainability. Environ. Monit. Assess. 51, 511-529.

Wahl, D.C., Baxter, S., 2008. The Designer's Role in Facilitating Sustainable Solutions. Des. Issues 24, 72-83.

Walter, C., Stützel, H., 2009. A new method for assessing the sustainability of land-use systems (I): Identifying the relevant issues. Ecol. Econ. 68, 1275-1287.

Wang, W., Duffy, A., Whitfield, I., Liu, S., Boyle, I., 2008. A design view of capability, in: Realising Network Enabled Capability Conference 2008, 13-14 October 2008, Leeds, UK. Leeds.

Wiersum, K.F., 1995. 200 Years of Sustainability in Forestry : Lessons from History. Environ. Manage. 19, 321-329.

Williams, C.C., Millington, A.C., 2004. The diverse and contested meanings of sustainable development. Geogr. J. 170, 99-104.

World Bank, 2010. Adjusted net saving - a proxy for sustainability. Adjust. net Sav. - a proxy Sustain.

World Commission on Environment and Development, 1987. Our common future. Oxford University Press, Oxford, New York.

Yang, C.-M., Li, J.-J., Chiang, H.-C., 2011. Stakeholders' perspective on the sustainable utilization of marine protected areas in Green Island, Taiwan. Ocean Coast. Manag. 54, 771-780.

Yang, H., Li, Y., Shen, J., Hu, S., 2003. Evaluating waste treatment, recycle and reuse in industrial system: an application of the eMergy approach. Ecol. Modell. 160, 13-21.

Yin, R., Xiang, Q., 2009. An integrative approach to modeling land-use changes: multiple facets of agriculture in the Upper Yangtze basin. Sustain. Sci. 5, 9-18.

Zhang, X., Deng, S., Zhang, Y., Yang, G., Li, L., Qi, H., Xiao, H., Wu, J., Wang, Y., Shen, F., 2011. Emergy evaluation of the impact of waste exchanges on the sustainability of industrial systems. Ecol. Eng. 37, 206-216. 
